\title{
The Special Programme of Research in Human Reproduction: Forty Years of Activities to Achieve Reproductive Health for All
}

\author{
Giuseppe Benagiano Catherine d'Arcangues Jennifer Harris Requejo \\ Alessandra Schafer Lale Say Mario Merialdi \\ UNDP/UNFPA/WHO/World Bank Special Programme of Research in Human Reproduction, World Health \\ Organization, Geneva, Switzerland
}

\begin{abstract}
The Special Programme of Research in Human Reproduction (HRP), co-sponsored by the UNDP, UNFPA, WHO, and the World Bank, is celebrating 40 years of activities with an expansion of its mandate and new co-sponsors.

When it began, in 1972, the main focus was on evaluating the acceptability, effectiveness, and safety of existing fertilityregulating methods, as well as developing new, improved modalities for family planning. In 1994, HRP not only made major contributions to the Plan of Action of the International Conference on Population and Development (ICPD); it also broadened its scope of work to include other aspects of health dealing with sexuality and reproduction, adding a specific perspective on gender issues and human rights. In 2002, HRP's mandate was once again broadened to include sexually transmitted infections and HIV/AIDS and in 2003 it was further expanded to research activities on preventing violence against women and its many dire health consequences.

Today, the work of the Programme includes research on: the sexual and reproductive health of adolescents, women, and men; maternal and perinatal health; reproductive tract and
\end{abstract}

sexually transmitted infections (including HIV/AIDS); family planning; infertility; unsafe abortion; sexual health; screening for cancer of the cervix in developing countries, and gender and reproductive rights.

Additional activities by the Programme have included: fostering international cooperation in the field of human reproduction; the elaboration of WHO's first Global Reproductive Health Strategy; work leading to the inclusion of ICPD's goal 'reproductive health for all by 2015 ' into the Millennium Development Goal framework; the promotion of critical interagency statements on the public health, legal, and human rights implications of female genital mutilation and genderbiased sex selection.

Finally, HRP has been involved in the creation of guidelines and tools, such as the 'Medical eligibility criteria for contraceptive use', the 'Global handbook for family planning providers', the 'Definition of core competencies in primary health care', and designing tools for operationalizing a human rights approach to sexual and reproductive health programmes.

Copyright $\odot 2012$ S. Karger AG, Basel

\section{KARGER}

Fax +4161306 1234

E-Mail karger@karger.ch

www.karger.com (c) 2012 S. Karger AG, Basel

0378-7346/12/0743-0190\$38.00/0

Accessible online at:

www.karger.com/goi
Dr. G. Benagiano, UNDP, UNFPA, WHO

World Bank

CH-2700 Geneva (Switzerland)

E-Mail pinoingeneva@bluewin.ch 


\section{Introduction}

The year 2012 marks the 40th anniversary of the Special Programme of Research, Development and Research Training in Human Reproduction (HRP), today a United Nations (UN) Programme, co-sponsored by the United Nations Development Programme (UNDP), the United Nations Population Fund (UNFPA), the World Bank and the World Health Organization (WHO). This year, the United Nations Children's Fund (UNICEF) and, through a special arrangement, the Joint United Nations Programme on HIV/AIDS (UNAIDS) also joined the group of sponsors. HRP is located at the WHO headquarters in Geneva, Switzerland, within the Department of Reproductive Health and Research (RHR).

Such wide support within the UN family should not create the impression that handling issues in human reproduction has always been an easy task for the WHO; in fact, the contrary is true and WHO entry into this field was initially met with disapproval by many of its members.

According to Dr. Alexander Kessler, the first director of HRP [1], the WHO first became involved in human reproduction following a request for technical assistance from the government of India in 1951 to carry out pilot studies of natural family planning (NFP) methods, with the aim of introducing the rhythm method into the country. The WHO participated in the studies and the results were published in 1954 [2].

The climate regarding family planning in those days was dramatically different from today and the mere suggestion of WHO participation in the UN World Population Conference of 1953 triggered some Member States to threaten to quit the Organization if this came to pass. Those opposed to WHO representation at the Conference argued that overpopulation is an economic and not a medical issue, that increased use of family planning would lead to an ageing of the world population and an eventual worsening of the ability of countries to provide health care and other services for their people, and that the duty of physicians is to promote human life, not to obstruct it [3]. This unfavourable climate prevented any involvement of the WHO in research on human reproduction for some 10 years. The WHO did not make a public statement on the topic until the Fourth World Congress on Fertility and Sterility in Rio de Janeiro, Brazil, on August 13, 1962, when Dr. M.G. Candau, the then director-general, asserted that issues in human reproduction represent 'a major public health problem because of the many social, cultural, economic, medical and biological factors involved' [4].

The Special Programme of Research in Human Reproduction
The subsequent year, 1963, marked the beginning of WHO's technical involvement in human reproduction a medical officer was appointed to specifically address issues related to human reproduction, and the first scientific group meeting to discuss issues in this field was convened. Over the next 6 years, 14 such meetings were held.

The year 1963 also represents the beginning of donor involvement in work concerning human reproduction. Thanks to a USD 500,000 grant from the US government, the field was reviewed and pilot studies were sponsored. This led to the establishment of a Human Reproduction Unit (the 'original' HRP) in 1965 which was headed by Dr. Alexander Kessler starting in 1966. The mandate of the Unit included advising Member States on family planning which resulted in receipt of a second grant of USD 400,000, this time from the government of Sweden. With this money, the Unit began working on family planning.

This early work led to the development of a feasibility project for a mission-oriented programme funded by four governmental agencies, those of Canada, Denmark, Norway and Sweden, and by the Ford Foundation.

\section{The Original Programme}

As a direct result of the feasibility study, and thanks to the foresight of Dr. Kessler and his trusted advisor Dr. Egon Diczfalusy of the Karolinska Institute, Stockholm, Sweden, the Expanded Programme of Research, Development and Research Training in Human Reproduction was formally established in 1972 [5].

Other governmental agencies and large foundations joined this first group of donors. The timing was perfect, since the overall climate had dramatically changed from the 1950s and a number of developing countries had become painfully aware of the need to achieve some form of population control. HRP immediately took a leadership role and went into action, creating task-oriented focus groups, a network of collaborating centres in all of the WHO's regions, and four main research and training centres to deal with family planning and infertility [6].

The first report on the Programme's activities, printed in 1972, listed the following initial areas of action:

- methods for the regulation of ovum transport;

- methods for the regulation of implantation;

- methods for the regulation (in the male) of the fertilizing ability of sperm;

- methods for the regulation of sperm migration and survival in the human female;

- prostaglandins in fertility regulation;

Gynecol Obstet Invest 2012;74:190-217 
- acceptability profiles of existing and potential methods of fertility control;

- the sequelae of induced abortion;

- ovulation detection, especially in relation to the rhythm method of birth control;

- the collection of baseline clinical and laboratory data relevant to the assessment of various methods of fertility control;

- agents stimulating gonadal function;

- pharmacological models for research and development of new contraceptives;

- mechanisms of hormone action and anti-hormones as related to fertility regulation;

- the sequelae of vasal occlusion.

Much has changed since the early days, not only in terms of research priorities but also in the Programme's structure and mechanisms of action as the Programme adapted to changing perceptions and needs.

\section{A New Structure and an Expanded Agenda}

As the scope and activities of HRP expanded and its visibility increased, discussions were held with other UN entities with the aim of joining forces and creating a unified research programme to better address health needs worldwide in the field of reproduction. This effort led to the creation of the co-sponsored Programme in 1988, as described previously.

The next key landmark in the evolution of the Programme was its response to the International Conference on Population and Development (ICPD) held in Cairo, Egypt, in 1994. This conference highlighted the links between population, health and development, but also denounced the use of women as the sole subjects of population policies. It marked a shift from large-scale family planning programmes to a focus on the needs and rights of individuals. As discussed later in this paper, the Programme made major contributions to the Plan of Action and broadened its scope of work beyond family planning and infertility to include other aspects of health dealing with sexuality and reproduction, adding a specific perspective on gender issues and human rights.

A major restructuring took place in 1998, when HRP and the Division of Reproductive Health, Technical Support (formerly the Division of Family Health), were joined to create the Department of Reproductive Health and Research, with HRP as its research arm.

In 2002, WHO's work on sexually transmitted infections (STIs) was transferred from the department in charge of fighting the infection caused by the human immunode- ficiency virus and the disease it causes, acquired immunedeficiency syndrome (HIV/AIDS), to RHR. This resulted in the grouping of all major elements of reproductive health under one leadership and a unified vision. This change also facilitated a more comprehensive approach to addressing STIs, rather than just through the lens of HIV.

The following year, the WHO's activities on preventing violence against women and its many dire health consequences were also integrated into RHR's programme of work.

These developments greatly expanded the scope and activities of HRP across the full spectrum of issues in sexuality and reproduction. The work of the Programme now includes maternal and perinatal health, reproductive tract infections (RTIs) and STIs (including HIV/AIDS), family planning, infertility, unsafe abortion, sexual health and gender and reproductive rights.

\section{Fostering International Cooperation}

One of the main features of HRP is to improve international cooperation in the field of human reproduction. Twenty years ago, Dr. Mahmoud Fathalla, a former director of the Programme, articulated three major reasons why such cooperation is essential [7]:

- the impact of the rise of the global population on the environment and the well-being of people - a phenomenon that transcends national boundaries;

- the time factor: action is needed urgently if disaster is to be avoided;

- the ethical imperative to eliminate great inequities in the level of health in the field of reproduction between developing and developed nations and between men and women.

\section{The Environment}

The impact of population growth and crowded environments on health and well-being is today recognized as a global, complex and difficult issue. The negative effects of environmental pollution on the reproductive system also surfaced as a global concern following the disasters of Seveso (Italy) in 1976, Bhopal (India) in 1984 and Chernobyl (at the time in the USSR, now in Ukraine) in 1986, among others.

In response, HRP decided that the relationship between population growth, environmental degradation and human reproduction needed careful investigation and convened a meeting in 1991 to examine the potential effects of a variety of environmental hazards on repro- 
duction [8]. The meeting documented the sensitivity of the reproductive system to adverse environmental conditions, with toxic environments increasing the risk of abortion, birth defects, foetal growth retardation and perinatal death. The meeting also underscored the point that in any unhealthy environmental situation the poor suffer disproportionately and in many settings the most vulnerable groups are women and children. In the mid1990s the Programme entered into negotiations for a USD 10 million grant to study possible effects of xenooestrogens on the reproductive process, but had to withdraw from the negotiating table when the prospective sponsors made publications of results conditional to their approval. Although environmental issues remain a hot topic, lack of funding has prevented HRP from engaging solidly in this field.

\section{The Need for Urgent Action}

Donors supporting the Programme have consistently agreed that priority-setting has to be achieved in consultation with developing countries who are the potential beneficiaries of HRP's research. Since the early days, all meetings organized to decide the priority agenda have included developing country representatives. Deciding on priorities was particularly important at times of financial difficulties, when certain lines of research had to be abandoned due to financial shortfalls. Over the years, setting priorities and the research agenda became a wellstructured exercise carried out by an ad hoc body, the 'Policy and Coordination Committee' (PCC). In June of 2012, the group held its 25th meeting and celebrated the 40th anniversary of the Programme (see box 1).

\section{Eliminating Disparities between Developed and}

Developing Countries

Today, global disparities in women's health continue to represent one of the starkest health inequities of our times. Huge inequalities in women's access to health care, such as skilled delivery and emergency obstetric care, family planning services, prevention and treatment of STIs and counselling for gender-based violence, remain within and between countries. These gaps make the need to adapt current knowledge and technology to lowresource settings both mandatory and urgent if the world is to achieve the development goals for the new millennium set by the UN (see below). Indeed, the real challenge is not to keep pace with major scientific advances in diagnosis and treatment but to overcome barriers to implementation and reach everyone with services that currently are only available to the lucky few.

The Special Programme of Research in Human Reproduction

\section{Box 1}

Policy and Coordination Committee (PCC)

List of Members 2012

Category 1 - Largest financial contributors in the previous (2010-2011) biennium:

China, Flemish Government (Belgium), France, India, Italy, Japan, The Netherlands, Norway, Sweden, Switzerland, UK

Category 2 - Countries elected by the WHO Regional Committees:

Bhutan, Bangladesh, Germany, Guatemala, Guinea-Bissau, Kenya, Lesotho, Liberia, Malaysia, Paraguay, Philippines, Thailand, Tunisia, Vietnam

\section{Category 3 - Other interested cooperating parties:} Nepal, Turkey

\section{Category 4 - Permanent members:}

(a) The cosponsors: UNDP, UNFPA, WHO, The World Bank (b) IPPF

The Special Programme is ideally positioned to respond to this challenge thanks to its extensive experience and unique standing within the UN system that affords it convening power and the ability to quickly enact decisions through its network of collaborating centres. Its research has highlighted the unacceptable vulnerability of disadvantaged population groups, as well as success stories [9], showing that when the right policies and programmes are in place and implemented with sufficient financial support, countries are able to narrow disparities in access, as well as improve women's health [10].

The Concept of Reproductive Health

One of the goals of a UN research programme is to define the field of action for international cooperation. In the mid-20th century, the approach in the international community to addressing the public health aspects of human reproduction was focused on 'maternal and child health'. The narrowness of this approach and its reminiscence of the Latin saying 'tota mulier in utero' (the entire woman is identified by her uterus) became evident in the early 1980s and 1990s following sweeping global sociodemographic changes. Widespread use of family planning and reduced global fertility [11] had opened up opportunities for women and increased awareness of their health needs beyond the pregnancy, delivery, and post-partum periods.

Gynecol Obstet Invest 2012;74:190-217 


\section{Box 2}

Definition of Reproductive Health as Approved at the International Conference on Population and Development in Cairo, 1994

(http://www.un.org/ecosocdev/geninfo/women/womrepro.htm)

Reproductive health is a state of complete physical, mental and social well-being and not merely the absence of disease or infirmity, in all matters relating to the reproductive system, and to its functions and processes. Reproductive health therefore implies that people are able to have a satisfying and safe sex life and that they have the capability to reproduce and the freedom to decide if, when and how often to do so. Implicitly in this last condition are the rights of men and women to be informed and to have access to safe, effective, affordable and acceptable methods of family planning of their choice, as well as other methods of their choice for regulations of fertility which are not against the law and the right of access to appropriate health care services that will enable women to go safely through pregnancy and childbirth and provide couples with the best chance of having a healthy infant. In line with the above definition of reproductive health, reproductive health care is defined as the constellation of methods, techniques and services that contribute to reproductive health and well-being by preventing and solving reproductive health problems. It also includes sexual health, the purpose of which is the enhancement of life and personal relations, and not merely counselling and care related to reproduction and sexually transmitted diseases.

Reproductive health realities in 1994:

- An estimated 1,600 women die every day from complications caused by pregnancy and child birth (99\% in developing countries)

- $\quad$ Each year, approximately 2 million girls are at risk of female genital mutilation

- About 70,000 women die every year from unsafe abortions, and many more suffer infections and other consequences

- Women are more likely than men to contract HIV through sexual encounters and about $42 \%$ of all persons infected with HIV are women

- $\quad$ Fifty-one percent of all pregnant women suffer from iron deficiency anaemia

- In many countries of South Asia, Africa, Latin America, and the Middle East, one third to one half of women are mothers before the age of 20

- Cancer of the cervix, the most common form of cancer in developing countries, is often linked to the sexually transmitted human papilloma virus

- Domestic violence, rape and sexual abuse are a significant cause of disability among women

To respond to this expanded definition of women's health and growing demand for new evidence and effective services, HRP's leadership began to work on a new concept: 'reproductive health'.

In the already mentioned Biennial Report celebrating the 20th anniversary of HRP, Dr. Fathalla, building on a definition prepared by his predecessor Dr. José Barzelatto, provided a first definition of reproductive health: 'Health is defined in the Constitution of the World Health Organization as 'a state of complete physical, mental and social well-being and not merely the absence of disease or infirmity'. In the context of this positive definition, reproductive health is not merely the absence of disease or disorders of the reproductive process, rather it is a condition in which the reproductive process is accomplished in a state of complete physical, mental, and social well-being. This implies that people have the ability to reproduce, that women can go through pregnancy and childbirth safely, and that reproduction is carried to a successful outcome, i.e. infants survive and grow up healthy. It implies further that people are able to regulate their fertility without risks to their health and that they are safe in having sex. The various elements of reproductive health are strongly interrelated, and improvement of one can facilitate the improvement of others (as indeed can the deterioration of one lead to the deterioration of others). While all elements of reproductive health are individually important, given the current socioeconomic and environmental conditions in the world, particularly in developing countries, fertility regulation is central to all other aspects of reproductive health. It has a bearing on, for example, the prevention of sexually transmitted diseases, the consequences of un- 
wanted pregnancy, infertility, sexuality, child survival, and safe motherhood [7].

With small modifications, the definition proposed by HRP was submitted to the ICPD held in Cairo in 1994 and was approved with only one amendment (see box 2) [12].

In 1995, the Fourth World Conference on Women (WCW) held in Beijing reaffirmed the concept to be redefined as sexual and reproductive health (SRH).

The Global Reproductive Health Strategy

Building on the international recognition of reproductive health, HRP was able to collaborate with countries in the elaboration of the WHO's first Global Reproductive Health Strategy (GRHS) [13]. This document, adopted by the 57th World Health Assembly in 2004, defines the five core elements of SRH as maternal and newborn health, family planning, unsafe abortion, STIs including HIV and RTIs, and sexual health. It reaffirms human rights as its guiding principle. It highlights five main areas for action: strengthening health systems capacity, mobilizing political will, creating supportive legislative and regulatory frameworks, and strengthening monitoring, evaluation, and accountability. As described later in this paper, HRP developed a number of methodologies and tools to operationalize this strategy.

\section{The STI Strategy}

The GRHS set the scene for the elaboration of areaspecific strategies and in May 2006 a Global Strategy for the Prevention and Control of STIs (GSPC-STI) was adopted by the 59th World Health Assembly [14]. It provides a framework for countries to understand the epidemiology of STIs in their populations, to improve and accelerate the implementation of their programmes and ensure that they are well linked with other SRH services. Reports on progress in implementing the GRHS and the GSPCSTI are provided to the World Health Assembly on a biennial basis.

The Millennium Development Goals

During the year 2007, HRP and its many international partners saw their efforts rewarded with the inclusion of the ICPD goal of 'reproductive health for all by 2015' into the Millennium Development Goal (MDG) framework. The original MDG framework adopted by 189 nations in 2000 made no mention of reproductive health. Multiple voices from academia, research institutions and development agencies responded to this omission by stressing that good reproductive health is essential to the attainment of several of the MDGs. Indeed, it underpins not only MDG 5 (improve maternal health) but also MDG 3 (gender equality), MDG 4 (reduce child mortality), MDG 6 (reduce HIV/AIDS), MDG 2 (improve access to education), MDG 1 (poverty) and MDG 7 (improve the environment). The evidence generated by HRP and others could no longer be ignored and the United Nations General Assembly of 2007 adopted the secretary-general's report recommending the inclusion under MDG 5 of an additional target, namely: 'achieve universal access to reproductive health' with the subsequent addition 'inadequate funding for family planning is a major failure in fulfilling commitments to improve women's reproductive health' [15].

The UN Secretary-General's Strategy for Women's and Children's Health

During the first decade of the new millennium, collaborative efforts among public health specialists and epidemiologists from developed and developing countries led to the production of a series of high-level publications in the scientific literature that highlighted the global burden of disease due to complications of pregnancy and childbirth, the major causes of child deaths, and cost-effective interventions that - if delivered at scale - could result in accelerated progress towards MDGs 4 and 5. This 'evidence-based advocacy' - most notably the Lancet series on maternal survival, newborn survival, child survival and SRH [16-18] - provided the basis for the engagement of global leaders, the heads of state of Canada, Chile, Ethiopia, Norway and Tanzania, as champions of maternal, newborn and child health $(\mathrm{MNCH})$ and helped position $\mathrm{MNCH}$ on the agenda of major political entities such as the G8, the African Union, the Asia Pacific Economic Cooperation Alliance and the International Parliamentary Union.

Building off of this momentum, the UN secretarygeneral issued a call for a joint plan for fulfilment of MDGs 4 and 5 in April 2010. This call was followed by a series of high-level events, including the joint Women Deliver/Countdown to 2015 conference, the G8 meeting with the Muskoka Initiative spearheaded by the Canadian leadership, the African Union Summit, the initiation of the Campaign for the Acceleration of Maternal Mortality Reduction in Africa and the G20 Summit. These events culminated in the launch of the Global Strategy for Women's and Children's Health by UN Secretary-General Ban Ki-moon in September 2010 at a United Nations General Assembly Summit [19]. 
The Global Strategy for Women's and Children's Health is an ambitious plan to save the lives of 16 million women and children by 2015 . It has mobilized an unprecedented commitment of over USD 40 billion from heads of governments and states, the private sector, academics, NGOs, health care programmes and UN agencies.

The WHO and HRP played a key role in the establishment of the time-limited Commission on Information and Accountability for Women's and Children's Health, charged with developing an accountability framework to monitor and track commitments made to the Global Strategy. The Commission's report published in 2011, 'Keeping Promises, Measuring Results', echoes the recent resolution of the United Nations Human Rights Council in stressing the fundamental human right of all women and children to health and includes ten recommendations for action. These recommendations have been translated into an action-oriented work plan that has the potential to radically transform women's and children's health worldwide.

Interagency Statements: Female Genital Mutilations, Gender-Biased Sex Selection

Interagency statements are powerful instruments to align action within the UN system to achieve specific objectives. HRP has been particularly active in contributing to two critical interagency statements on the public health, legal and human rights implications of female genital mutilations (FGM) and gender-biased sex selection (GBSS).

The statement aimed at eliminating FGM was published in 2008 and has been signed by 10 UN agencies [20], expanding upon the 1997 joint statement published by the WHO, UNICEF, and UNFPA. The increased support base within the UN system reflects growing interest in ending FGM by improving legal frameworks to incorporate basic human rights principles, and by increasing awareness of its negative consequences for the health of girls, women, and newborns. The document was followed by the publication in 2010 of a global strategy to stop health care providers from performing FGM, signed by $10 \mathrm{UN}$ agencies and international federations [21].

The second statement decries another detrimental practice still in widespread use in certain parts of the world: GBSS and infanticide [22]. The document stresses the negative consequences of a systematic preference for boys and associated practices (prenatal sex detection and selective abortion, infanticide and neglect of the girl child) still rooted in many cultural traditions. It reminds
UN Member States of their obligation under human rights laws to respect, protect and fulfil the human rights of girls and women. This obligation exists for the more than 180 States signatories to the 1994 Programme of Action of the ICPD who have agreed to 'eliminate all forms of discrimination against the girl child and the root causes of son preference, which result in harmful and unethical practices regarding female infanticide and prenatal sex selection' (paragraph 4.16) [12].

The joint interagency statement reaffirms the commitment of UN agencies to uphold the ICPD Programme of Action and to provide recommendations for governments and organizations on how best to tackle this issue. The complexity of sex selection practices including GBSS makes interagency alignment on the development and implementation of a plan for effective advocacy and action at multiple levels essential.

\section{The Work of the Programme}

Since its early days, HRP has taken on a leadership role in evidence generation and in the translation of evidence into action. It is impossible to adequately discuss here all the work carried out by HRP over the last 40 years. Instead, this section provides a snapshot of HRP's ten main research areas and major contributions to the field of SRH.

Work by the Programme in infertility is described separately in this issue of Gynecologic and Obstetric Investigation [23] and therefore is not discussed here.

\section{(1) Research Capacity Strengthening}

\section{Strengthening Institutions}

Since its inception, the Programme has aimed to strengthen countries' capacity for research in reproductive health, devoting a third of its resources to this goal. Its main strategy has been to support research institutions in order to enhance their potential to implement activities relevant to national and regional needs, and to facilitate their participation in global research efforts. Over time, the mechanisms used for grant-making have evolved and currently include: long-term (10 years) institutional development grants, research training grants, re-entry grants to facilitate the return of scientists to their home institutions, research project mentoring grants to 'service guidance centres' charged with disseminating the work of the Programme and other evidence-based 
guidance, competitive intraregional research grants, and grants for courses, workshops or seminars.

Over 40 years, this investment enabled the establishment of a network of more than 120 supported institutions in nearly 60 countries in all six WHO regions. These institutions are today capable of undertaking national and international research; some centres have become regional training centres, and others are engaging in ever-increasing South-to-South and intraregional collaboration.

\section{Bioethics}

Today every investigation involving human subjects is routinely scrutinized by the ethical review board of the institution responsible for carrying out the study. Such a safeguarding process was not in place in 1972 when the Programme initiated its activities, and the pioneering role it played in developing ethical standards of research must be recognized. HRP created a Scientific and Ethical Review Group at the time of its inception and every protocol developed by the Programme, as well as every study supported by it, is submitted to careful ethical scrutiny.

In HRP's early days, this procedure was considered unusual and oftentimes an unnecessary obstacle to research, to the point that individual centres sometimes altered the description of the Informed Consent Form prepared by HRP when translating it into local languages to make it 'more palatable' to prospective subjects. For this reason, the Programme took particular care to supervise translations to ensure full protection of human subjects involved in its research.

Over time, Ethics Committees were created in a number of countries and two additional bodies were established at the WHO's headquarters: the Toxicology Review Group and the WHO's Secretariat Committee for Research Involving Human Subjects (today called WHO's Research Ethics Review Committee).

\section{(2) Provision of High-Quality Family Planning Methods and Services}

\section{Acceptability of Fertility-Regulating Methods}

Social and individual acceptance of family planning methods is a priority area of research today. From its inception, HRP has engaged in this area of research with the aim of planning and conducting research on the characteristics of different methods of family planning that affect their acceptance in various sociocultural settings.

Since the advent of modern contraception, biomedical scientists have focused mainly on understanding the physiological steps in reproduction susceptible to interference. The development of effective methods, however, did not necessarily translate into their rapid uptake around the world. Acceptability studies were, as a consequence, introduced to gain a better understanding of the factors determining the practical success of different contraceptive modalities. The findings would, in turn, be used to help biomedical researchers develop more widely acceptable and culturally appropriate methods.

During the initial years of HRP work in family planning, research was carried out in the following areas: preferences for different routes of administration of contraceptive agents, relative acceptability of reversible and irreversible sterilization, sociocultural acceptability of amenorrhoea and other side effects associated with different contraceptive methods, identification of desirable features of methods for regulating male fertility, and the relative importance of such factors as effectiveness, safety, ease of use, and cost, in the individual choice of method.

As described in (9) SRH Programmes and Services, in 1985 the scope of work in this area was expanded through the creation of a Task Force on Social Science Research.

\section{Natural Family Planning}

The so-called methods for the natural regulation of fertility are based on a careful, but simple, detection of the fertile period in a woman's menstrual cycle. Over the years a number of modalities have been developed in this area and, more recently, several tools have been created to facilitate this detection, thereby shortening the period of abstinence during potentially fertile days.

Initially, the Programme's involvement in research on NFP methods had three specific objectives: validate and improve the effectiveness of existing modalities based on periodic abstinence, reduce the duration of use of additional methods of fertility regulation (e.g. condoms or, potentially, post-coital methods) that might be used by some in connection with NFP, and permit improvement of timing of intercourse when pregnancy is desired.

The objectives were successively broadened to include the development of simple kits and devices to enable women to detect their fertile period, the improvement and standardization of methods for teaching NFP, and research on lactation as a fertility regulating method, i.e. the lactational amenorrhoea method (LAM).

By the early 1980s the results of a multicentre, 10 -country study provided precise information on the temporal relationships between ovulation and defined changes in the concentration of plasma oestradiol-17 $\beta$, 
luteinizing hormone, follicle-stimulating hormone, and progesterone and the time of ovulation as determined by direct visualization and histological assessment of the ovaries $[24,25]$. In addition, a careful determination was also carried out to ascertain the temporal relationship between various indices of the fertile period [26].

HRP also conducted a multicentre, 5-country, unbiased assessment of the 'ovulation method' optimized and promoted by two Australian physicians, John and Lynn Billings, and based on the self-evaluation of changes in cervical mucus. The study involved more than 850 subjects and was divided into two parts. First an individual woman's ability to self-detect the fertile period was tested. During this phase, $5 \%$ of the women experienced an unplanned pregnancy. In the second phase, 725 subjects were followed over 1 year to evaluate the method's effectiveness, with an overall pregnancy rate of 22.5 per 100 woman-years. Although this figure is high, it must be noted that the most common reason for pregnancy was a conscious departure from the rules of the method. The study established the effectiveness of the method when couples carefully adhere to the rules, but also highlighted the fact that departure from the rules and, therefore, failures were common [27-31].

In 1979, while the above described studies were being conducted, the Advisory Group to the Programme, determined that this area of research had 'very limited application, particularly in developing countries' and recommended that - with the exception of work on kits to determine the fertile period - HRP devote no additional efforts to this area of research.

Over the subsequent years, the Programme continued its involvement in the development of objective methods to predict and detect ovulation as a reference method to identify the beginning of the fertile period [32-34], but did not greatly expand research activities in this area.

More recently, HRP focused its attention on the LAM, based on the observation that women who breastfeed are less likely to ovulate early post-partum and that they are less likely to experience a normal ovulation prior to the first menstrual bleed, if they practice exclusive breastfeeding [35].

Based on these data, the Programme initiated a multicentre, multinational study of breastfeeding and the LAM. The study involved 4,118 subjects and found substantial differences between centres in the duration of amenorrhoea, ranging from a median of 4 months in India to 9 months in China. Differences were also observed in the timing of supplementation. The results indicate that breastfeeding promotion and family planning ad- vice should be site and culture specific. Ten factors were significantly related to the duration of amenorrhoea. Seven of these are related to infant feeding practices, indicating that sociocultural factors play an important role in variations in feeding patterns and in the rate of amenorrhoea. The remaining three were high parity, low body mass index, and a higher frequency of infant illness. $\mathrm{Cu}-$ mulative pregnancy rates during amenorrhoea in the first 6 months after childbirth ranged from 0.9 to $1.2 \%$ during full breastfeeding. At 12 months, the rates ranged from 6.6 to $7.4 \%$ during full breastfeeding and from 3.7 to $5.2 \%$ up to the end of partial breastfeeding. Finally, the duration of lochia varied significantly across study populations, and long durations were not unusual. The significance of the end-of-puerperium bleeding episode is unknown and most users of LAM will not experience a post-lochia bleeding episode before post-partum day 56 [36-39].

More recently, the Programme collaborated with Georgetown University in the USA in the development of simpler methods, such as a new calendar-based method called the 'standard days' method, and in using its Strategic Approach [40] to facilitate the introduction of these methods into national family planning programmes.

\section{Research, Development, Safety and Clinical Use of Long-Acting Hormonal Agents}

One of the areas in which HRP has provided a major contribution is research on long-acting contraception. In the 1970s, a major controversy surrounded the only widely utilized long-acting hormonal contraceptive: the 3-monthly injectable depot-medroxyprogesterone acetate (Depo-Provera, or DMPA), because of animal data showing that it increased the risk of breast cancer in female beagle dogs [41]. This finding prohibited the US Agency for International Development (USAID) from providing Depo-Provera to developing countries. In addition, many countries were reluctant to use a drug not approved in its country of origin (the USA) [42]. The Programme decided to act decisively and embarked on a series of studies proving DMPA's great effectiveness, clinical safety and usefulness in the developing world [43-47]. To further reassure users, the Programme carried out a large, multicentre case-control study demonstrating that the use of this injectable contraceptive was not associated with an overall increase in the risk of breast cancer. This finding convinced the US Food and Drug Administration (USFDA) to approve DMPA for contraceptive use, and the use of this method in developing countries subsequently increased [48]. 
The Programme also worked on another long-acting progestin, norethisterone enanthate (NET-EN), injected intramuscularly at the dose of $200 \mathrm{mg}$, to define its duration of action, its clinical characteristics and its effectiveness $[49,50]$.

The WHO-Sponsored Chemical Synthesis

Programme

Recognizing that the pharmaceutical industry was not showing sufficient interest in the development of new long-acting progestins, the Programme launched a major initiative in 1975 aimed at the chemical synthesis and screening of a large number of progestin and androgen derivatives that could be formulated as monthly, threemonthly, and 6-monthly preparations to be used both in women and men.

The development of new agents requires a concerted effort to synthesize novel long-acting steroid derivatives, screen them and carry out animal biological evaluation to determine which compounds are suitable for testing in the human. Such an effort had never been carried out outside the pharmaceutical industry; for this reason, the Programme decided that the synthetic work should be combined with an institution-building exercise in developing countries, although patent rights would remain with the WHO. It was felt that this work could conceivably serve as a model for other drug development programmes targeted at the developing world, to fight diseases such as leishmaniasis, schistosomiasis, and onchocerciasis [51]. To simplify matters, the synthetic effort focused on creating long-acting esters of known steroids, rather than on synthesizing novel moieties. Three target areas were selected to achieve this objective [52]: (a) 3-6 month progestin-only injections, (b) monthly oestrogenprogestin injections, and (c) long-acting testosteroneprogestin combinations. Besides testosterone, two moieties known to be safe and effective as contraceptive progestins were selected: norethisterone and levonorgestrel (LNG). To prolong the duration of action the free 17-hydroxyl group was to be esterified in such a way that after administration enzymatic hydrolysis would convert the 'prodrug' into an active contraceptive agent [51]. After completion of the synthetic work, the samples were submitted to quality control, purification whenever necessary, and formulation. Following bioassay, a few suitable esters were identified.

The synthetic and screening work, as well as some aspects of the quality control, formulation, studies of the rate of enzymatic hydrolysis and the biological evaluation in animals of the androgen and progestin derivatives, has been fully reported in an ad hoc issue of the international journal Steroids [53].

Several compounds proved to be longer acting than the two standard compounds DMPA and NET-EN, although for financial reasons further development continued with only three progestin derivatives being of particular interest: LNG butanoate, LNG cyclopropyl-carboxylate, and LNG cyclobutyl-carboxylate.

In the 1990s, always because of financial constraints, the Programme decided to proceed with only one progestin (LNG butanoate; LNG-BT) and one androgen (testosterone bucyclate; T-BC).

LNG-BT can provide contraceptive protection at a dose of 5-10 mg every 3 months and would therefore impose a lower body burden than DMPA, possibly resulting in less ovarian suppression, less amenorrhoea and a more rapid return of fertility. An optimal particle size was determined and a manufacturing process was established. Pharmacokinetic/pharmacodynamic studies in women suggested that the final dosage required for 3 months of contraceptive coverage will be $10 \mathrm{mg}$ or less. Based on these results, an Investigational New Drug application was filed with the USFDA for this compound [54]. After a period of no activity due to legal issues connected with insurance necessary to conduct human studies, a confidentiality agreement was signed between the WHO, the US National Institute of Child Health and Human Development (NICHD) and the Contraceptive Research and Development Programme (CONRAD) in 2004 for a collaborative effort to further develop this compound. During 2006, extensive re-evaluation of the physical and chemical properties was performed [55] and more recently CONRAD has been working with NICHD in manufacturing a clinical batch for a human study. Choosing the right particle size is an essential step in developing a long-acting injectable, and much depended on this initial human pharmacokinetic study. Unfortunately, results were unsatisfactory and new formulations using several different particle sizes are at present being evaluated. No further human trial is expected until 2013.

\section{Development of Monthly Oestrogen-Progestin}

Combinations

The main reasons women discontinue use of progestin-only injectable contraceptives such as DMPA are menstrual disturbances, in particular heavy bleeding, irregular, unpredictable bleeding and amenorrhoea. In the 1970s, to offer women an alternative, HRP undertook a review of all available combined, monthly preparations and decided to optimize the dosage and the progestin/ 
oestrogen ratio of two products, Cyclofem and Mesigyna, and to oversee their clinical evaluation.

Early dose-finding studies [56] showed that effectiveness would decrease with a low progestin/oestrogen ratio, while cycle control would decrease if this ratio was too high. Thus the optimal compositions were found to be 25 $\mathrm{mg}$ DMPA plus $5 \mathrm{mg}$ oestradiol cypionate for Cyclofem, and $50 \mathrm{mg}$ NET-EN plus $5 \mathrm{mg}$ oestradiol valerate for Mesigyna. Subsequent pharmacokinetic, pharmacodynamic $[57,58]$ and metabolic studies [59-61] and clinical trials [62-67] established the efficacy and safety of both preparations. Introductory studies followed in a number of countries $[68,69]$, illustrating a variety of experiences and service delivery issues.

Currently, each preparation is registered in over 35 countries and an estimated 8 million women use a oncea-month injectable preparation.

Safety and Efficacy of Subcutaneous Implants

Contraceptive implants have been introduced in national family planning programmes since the mid-1980s. Because most of the evidence gathered on these methods came from their developers, HRP was asked for an impartial neutral assessment. In 1984, the Programme convened a meeting of experts to review the full body of evidence on all implants then available, confirming their high level of effectiveness and safety [70]. It carried out a number of clinical trials on the side effects of the first implant to be in wide use, the six-rod LNG-releasing Norplant implant, investigating its effects on lipid metabolism [71] and on endometrial bleeding [72-74].

Currently, it is finalizing a randomized clinical trial to assess the clinical performance and contraceptive efficacy of two contraceptive implants, Jadelle and Implanon, in 7 countries: Brazil, Chile, the Dominican Republic, Hungary, Thailand, Turkey, and Zimbabwe. A total of 2,008 women were randomized to receive one of the two implants, and an age-matched cohort of 973 women who elected to use the TCu380A IUD was enrolled in parallel to the randomized trial. Whereas Jadelle is registered for 5 years and Implanon for 3 years, the main objectives of the randomized trial are to compare both methods over 5 years of use in terms of continuation, effectiveness and side effects; these studies are ongoing.

\section{Hormonal Contraception and Neoplasia}

The WHO Collaborative Study of Neoplasia and Steroid Contraceptives was launched in 1985 to address an important issue in post-marketing surveillance of hormonal contraception.
For this purpose the Programme initiated a large, hospital-based case-control study in 8 developing and 3 developed countries to determine whether use of combined oral contraceptives alters the risk of various cancers. The investigation found a trend of increasing risk of invasive cervical cancer with duration of use of combined hormonal contraceptives (COC), although the finding may not represent a causal relationship. In contrast, there was a decreased risk of ovarian and endometrial carcinomas in users indicating a protective effect of COC, the degree of which was similar in developing and developed countries. A small increase in the risk of breast cancer in recent and current users was found to be somewhat greater in developing countries than in developed countries and both causal and non-causal interpretations of this finding have been presented. No associations were found between oral contraceptives and in situ cervical, hepatocellular, cholangio, or gallbladder carcinomas, or uterine sarcomas. Unfortunately, the power of the study to detect alterations in risks of these neoplasms in long-term users was low [75-82]. The Programme also extensively investigated a possible association between use of Depo-Provera and risk of neoplasia. The results showed that the relative risk (RR) of breast cancer for women who had ever used DMPA was 1.1 (95\% CI 0.97-1.4), with no increase in risk with increasing duration of use of DMPA, with recent (or current) use being the key factor. A small increased risk observed in recent (or current) users might have been due to enhanced detection of breast tumours or to acceleration of the growth of pre-existing tumours $[83,84]$. No increased risk of epithelial ovarian or invasive squamous cell cervical cancers was found, with an RR estimate of 1.07 (95\% CI 0.6-1.8) for the former and 1.11 (95\% CI 0.96-1.29) for the latter. In both cases, no trends in risk with duration of use or time since the initial or most recent exposure were observed $[85,86]$. A marked decrease in the risk of endometrial carcinoma was observed. The RR was estimated to be 0.21 (95\% CI 0.060.79). All 3 exposed pre-menopausal cases with an endometrial cancer had also received oestrogens [87]. Finally, there was no significant association with risk of hepatocellular carcinoma or cholangiocarcinoma [88].

\section{Copper-Releasing Intrauterine Devices}

When HRP initiated its work, intrauterine contraception was practiced with inert devices. For this reason, the Programme included 'medicated intrauterine devices' in its original list of areas for involvement.

Information gathered by the WHO up to 2007 indicated that intrauterine devices/systems (IUD/IUS) repre- 
sented the most widely utilized method of reversible contraception and were used by $14.5 \%$ of women of fertile age in the developing world. This percentage, however, decreased to $7.6 \%$ in the industrialized world [89].

Today only medicated IUD/IUS are utilized: those releasing copper ions (Cu-IUD) and those releasing a progestin (Mirena).

HRP was a pioneer in the field of research on $\mathrm{Cu}$ IUDs, defining their true duration of action. During the 1980s these devices were approved for only 4 years, with little data beyond that. For this reason, the Programme embarked on long-term studies with several $\mathrm{Cu}$-IUD models [90] obtaining proof that the T-Cu220C and the T-Cu380A were active for at least 9 years. With regard to the TCu220A, pregnancy rates were 4.9 and $5.4 \%$ and with the TCu380A they were 1.7 and $2.1 \%$ per 100 woman-years at 7 and 9 years.

Based on effectiveness data obtained by the WHO, the USFDA extended the approved time frame for use of the TCu380A from 4 to 6 years in 1989 and further extended the approval to 8 years in 1991 [91]. Today, the FDA approval is for 10 years. It is noteworthy that although the effectiveness of the TCu220A is lower than that of the TCu380A its discontinuation rates are also lower [92].

HRP also conducted a randomized, multicentre, comparative study of the TCu380A and a device called Multiload (ML) Cu375, designed in 1972 by van Oss. The trial was initiated in 1989 and several analyses were published [93-95]; the study found lower pregnancy rates (both intrauterine and ectopic) with the TCu380A.

\section{Emergency Contraception}

The original plan of action drawn up in 1972 included a Task Force on 'Methods for the Regulation of Ovum Transport' with three objectives: (a) new chemical and surgical methods for occluding the fallopian tubes, (b) post-coital contraceptives, and (c) the effect of drugs on ovum transport and ovum survival in women. Specifically, HRP felt that 'For many women the availability of a pill that could be taken after intercourse would represent an attractive method of contraception. Such a method would be particularly useful for women having infrequent intercourse, or for emergency use. The large doses of oestrogen that have been given in the past for these purposes have been associated with a high incidence of unpleasant side effects. The Task Force research proposes to evaluate several promising progestational agents through collaborative trials involving the collaborating centres'.

The progestin selected for this work was LNG and, after preliminary studies [96], the effect of a dose of $600 \mu \mathrm{g}$
LNG was compared for the first time to the classic oestrogen regimen (known as the 'Yuspe regimen' [97]). At this stage, HRP sponsored a multicentre trial of the contraceptive efficacy and side effects of LNG administered during the periovulatory period, utilizing a mean number of four $0.75-\mathrm{mg}$ LNG tablets. The study demonstrated not only the high effectiveness of this regimen but also the greatly reduced frequency and severity of side effects [98]. In a subsequent, large, prospective, randomized trial the Programme compared the effects of LNG $(750 \mu \mathrm{g}$, taken twice $12 \mathrm{~h}$ apart) with the Yuzpe regimen. The progestin-only method not only proved to be more effective but also produced significantly lower side effects [99].

Today, the dosage recommended by the WHO is 1.5 mg LNG, as a single dose taken as soon as possible after unprotected intercourse; alternatively, and with seemingly equally good results, two doses of $0.75 \mathrm{mg}$ can be taken at a 12-hour interval $[99,100]$. With regard to side effects, nausea and vomiting (the most common side effects observed in women using the Yuzpe regimen) are less common after the use of the LNG-based method (18.8 vs. $5.6 \%$, respectively). At any rate, if a woman experiences an episode of vomiting within $2 \mathrm{~h}$ of taking the medication, the dose should be repeated. Cycle disturbances have been reported following the use of both methods, although in approximately $60 \%$ of users of both methods menses will return on the expected date [100].

The LNG method is definitely more effective if used within $72 \mathrm{~h}$, even though there is still some effect for the first 5 days after unprotected intercourse. Failure rates have been calculated in the range of $2 \%$, with the risk of an unwanted pregnancy being reduced by $60-93 \%$ [100].

A new class of compounds, named antiprogestins or selective progesterone receptor modulators, exists today that can be utilized for EC. The Programme has contributed in a substantial way to the development of the first of these substances, mifepristone or RU-486, as an emergency contraceptive. In a series of preliminary trials, dosages ranging between 600 and $50 \mathrm{mg}$ have been tested, all with promising results [101]. Following up on these results, HRP conducted a further multicentre study including a sixty-fold reduced dosage $(10 \mathrm{mg})$ and found no difference between $600 \mathrm{mg}$ [ 7 pregnancies $(1.3 \%)$ out of 559 women], $50 \mathrm{mg}$ [6 (1.1\%) out of 560] and $10 \mathrm{mg}$ [7 (1.2\%) of 565] when administered up to $120 \mathrm{~h}$ after unprotected intercourse [102]. An initial study also showed that the effectiveness of a single dose of $10 \mathrm{mg}$ mifepristone was not different from that observed with the two already available LNG regimens [103]. However, a subsequent Cochrane review [104] concluded that doses of mifepris- 
tone between 25 and $50 \mathrm{mg}$ are superior to other hormonal regimens. Also low doses of mifepristone $(<25$ $\mathrm{mg}$ ) are probably more effective than two doses of LNG $0.75 \mathrm{mg}$, although no conclusive evidence was found at the time.

Today RU 486 is available in China at the doses of 10 and $25 \mathrm{mg}$.

\section{Implementation Research}

Historically, HRP has been highly recognized for conducting large clinical trials to test the safety and effectiveness of interventions aimed at improving SRH, especially in low-resource settings. In recent years, interest in how to implement and scale-up effective interventions has escalated within the international community and the concept of implementation science has become familiar to researchers, programme implementers and funding agencies. HRP actively contributed to this area of work by publishing methodological articles discussing and categorizing the different dimensions of implementation research [105] and its application to reproductive health $[106,107]$, and by supporting groups engaged in this type of research around the world.

During the last decade HRP developed a wide range of research activities in the field of implementation science deploying a multidisciplinary approach, involving experts in programme implementation, health systems/operation implementation research, SRH delivery services, clinical interventions, health sector development, policy, behavioural and organizational sciences, monitoring and evaluation.

Health systems research has focused on testing strategies aimed at increasing the performance of the system by health system financing reforms, improved governance, aid effectiveness innovations and partnership with the private sector. Concrete examples of this kind of research include a study to determine the effect of a performance-based payment scheme for public sector providers of reproductive health services in Egypt [108] and an evaluation of the impact of health system improvements on pregnancy outcomes in the Philippines [109].

An issue of particular concern for HRP and its constituency is the often slow uptake of clinical research findings and evidence-based practices into clinical care, especially for interventions for which HRP conducted original research. Therefore, the Programme engaged in a research project aimed at testing the effect of multifaceted interventions to increase compliance with $\mathrm{WHO}$ guidance for clinical practice. Examples of these studies include the evaluation of a very successful intervention to increase the use of evidence-based birth practices (use of oxytocin during the second stage of labour and selective episiotomy) in Latin American hospitals [110] and the determination of the lack of effect of two interventions aimed at increasing the quality of obstetric care - the use of the WHO Reproductive Health Library (RHL) and the reduction in the use of unnecessary caesarean sections (CS) through a policy of mandatory second opinion [111, 112].

To assure that research results will contribute to increasing access to quality SRH services it is critical that the translation of evidence not be limited to clinical practice but extend to policies and programmes. Over the last 17 years, HRP has developed a systematic evidence-based approach to reproductive health policy and programme development. This process is widely known as the WHO Strategic Approach to SRH policy and programme development. In addition to the Strategic Approach, HRP has contributed to the development of the ExpandNet network for designing scaling-up strategies $[113,114]$.

\section{Guidelines and Tools}

National family planning programmes face a double challenge: to ensure that the care they provide is of high quality, and to reach the widest possible audience. To support them in these efforts, HRP and its partners initiated a system for continuous identification of research evidence (CIRE) $[115,116]$. This allows RHR to keep a finger on the pulse of research findings and to ensure that the guidance it produces is based on the latest available evidence.

This guidance consists of four main documents:

- Medical eligibility criteria for contraceptive use: this guide is targeted at policy makers and programme managers. It provides guidance on the choice of contraceptive methods suitable for women with various medical conditions. It is available in multiple languages; the latest (fourth) edition was published in 2010 [117] and work towards the next edition is in progress. A companion job aid - the 'Medical eligibility criteria wheel' - was designed to provide the information in summary form for quick reference for family planning providers in their daily work.

- Selected practice recommendations for contraceptive use: this publication provides guidance on the use of contraceptives, with the goals of maximizing effectiveness and managing side effects and other problems [118]. This document is available in multiple languages.

- Decision-making tool for family planning clients and providers: this guide - developed in collaboration with 
Johns Hopkins University Center for Communication Programs (JHU/CCP) - focuses on the client-provider interaction in family planning, and in particular the processes of decision making and problem solving [119]. Development of the tool involved formative workshops with providers in Indonesia, Mexico, South Africa and Trinidad and Tobago and observational evaluation research in Indonesia, Mexico and Nicaragua [120]. Client-provider communication and decision-making assessment were qualitatively performed through an analysis of videotaped counselling sessions. Additional qualitative data from providers and clients were collected through focus group discussions, interviews and a questionnaire.

This tool was completed and published in 2005, translated into 26 languages and adapted for use in multiple family planning programmes.

- Global handbook for family planning providers: in partnership with JHU/CCP, and in collaboration with over 20 reproductive health organizations and agencies, RHR developed a handbook for clinic staff, now available in 14 languages [121].

\section{(3) Induced Abortion and Its Consequences}

Induced abortion is arguably one of the most controversial issues in the field of medicine and, for this reason, the Special Programme has never attempted to interfere with the right of individual Member Countries to legislate in this field. However, given that unsafe abortion is a major cause of maternal deaths and that there are many other health consequences of pregnancy termination, HRP decided from its inception that research in this area could not be left out of its agenda. As documented in the first report of the Programme's activities, a Task Force was established in 1972 to document immediate, shortand long-term sequelae of legal abortion. Both retrospective and prospective studies were carried out to evaluate sterility associated with prior induced abortion, as well as the outcome of pregnancy following induced termination. A detailed report on these early studies was published in 1977 [122].

In this connection, it is worth mentioning that when the HRP initiated its work, all methods available for inducing an abortion were either surgical or utilized the injection of strong (sometimes toxic) irritants into the amniotic cavity [6]. For this reason, the Programme conducted a multicentre study of seven natural and synthetic prostaglandins and established which regimens and doses were the most appropriate for pregnancy termination [123].

HRP's key contribution to improving the safety of abortion procedures is its work towards the development and wide acceptance of medical abortion regimens. The Programme carried out a number of multicentre randomized clinical trials to establish the optimal doses and routes of administration for both the mifepristone-misoprostol combination and misoprostol alone [124-130]. However, the limited availability of mifepristone, due to lack of licensing and registration and its price, remained a barrier to the wider use of medical abortion. Thus, to facilitate access to drugs used for medical abortion, HRP collaborated with the Concept Foundation, a not-for-profit organization, and an Indian pharmaceutical company in developing a pre-packaged preparation of mifepristone and misoprostol, called Medabon ${ }^{\circledR}$. The preparation consists of $200 \mathrm{mg}$ mifepristone ( 1 tablet) to be taken on day 1 , and $0.8 \mathrm{mg}$ misoprostol (4 tablets) to be taken on day 2 or day 3 , a regimen which results in complete abortion in more than $96 \%$ of cases. An agreement with the manufacturer and national governments that import the product makes the mifepristone-misoprostol combination available at a preferential price for purchase by the public sector in developing countries where the regimen is registered. Currently, Medabon is registered in some 20 developed and developing countries.

The introduction of safe medical abortion requires much more than registration and marketing of drugs in the relevant country. HRP has been instrumental in initiating a strategic approach in which the current provision of a service and potential approaches for improving that provision are explored before recommendations to introduce a new technology are made. Such strategic assessments were performed in countries as varied as Bangladesh, Ghana, Guinea, Kyrgyzstan, Malawi, Moldova, Mongolia, Romania, Senegal, Ukraine, Vietnam, Zambia and others [e.g. 131-133].

Access to safe abortion as well as to other interventions may be limited due to lack of availability of physicians, as is often the case in low-resource settings. HRP coordinated two critical clinical trials in Nepal, South Africa and Vietnam showing that mid-level providers can safely administer medical abortion regimens and perform manual vacuum aspiration for first-trimester abortion, independently from and as safely as medical doctors [134, 135].

Assuring access to safe abortion, when permitted by law, by developing more acceptable methods and cost- 
effective service delivery modalities is critical as shown by a recent analysis of incidence and trends of induced abortion worldwide from 1995 to 2008 conducted by HRP and the A. Guttmacher Institute. The study produced evidence that the proportion of all abortions that are unsafe has increased over time and that interventions to reduce unintended pregnancy and unsafe abortion, including investments in family planning and safe abortion care, are needed in the context of the global effort to achieve the MDGs [136].

Therefore, appropriate translation of research results into clinical practice and public health policy is a major challenge for countries where abortion is legal. To assist governments, public health authorities, NGOs and specialized agencies in this task HRP regularly updates and revises the manual 'Safe abortion: technical and policy guidance for health systems'. The last edition of the document was published in 2012 reflecting changes in methods of abortion and related care, service delivery, and application of a human rights framework for policy-making related to abortion [137].

\section{(4) Antenatal, Delivery, Post-Partum and Newborn} Care

HRP's work in the area of maternal and perinatal health focused originally on the main causes of maternal mortality such as eclampsia and post-partum haemorrhage. The Eclampsia and Magpie trials sponsored by HRP in the 1990s demonstrated with clear-cut results and sound methodology that magnesium sulphate $\left(\mathrm{MgSO}_{4}\right)$ is the drug of choice for managing pre-eclampsia/eclampsia. Both studies are often presented in the literature as examples of how to design and conduct large randomized clinical trials [138, 139].

After having clarified management issues of pre-eclampsia/eclampsia, in the 2000s HRP's work focused on testing the effectiveness of preventive strategies by conducting two large multicountry studies on calcium and antioxidant supplementation during pregnancy. While calcium supplementation was shown to reduce the risk of severe complications of pre-eclampsia, antioxidant supplementation did not show any beneficial effect [140].

Presently the work of HRP in pre-eclampsia is focusing on the identification of biomarkers for its early prediction, the validation of algorithms for the identification of women at risk of negative outcomes after hospitalization for pre-eclampsia and the development of simplified and easy-to-use delivery systems for $\mathrm{MgSO}_{4}$ $[141,142]$.

As post-partum haemorrhage represents the major cause of maternal mortality worldwide, HRP invested considerable resources in trials to determine the effectiveness of preventive and treatment regimens for this condition. Two large multicentre trials confirmed oxytocin as the drug of choice for its prevention and treatment $[143,144]$.

The recently published results of a multicentre trial showing that a simplified active management of the second stage of labour is as effective as the standard one in preventing post-partum haemorrhage represent another example of how HRP research findings can be used to inform clinical practice [145].

For the immediate future there are high expectations for the forthcoming publication of an HRP-supported, randomized clinical trial conducted in Africa to test the effectiveness of a relatively simple and low-cost device, the 'anti-shock non-pneumatic garment', in reducing the risk of death from hypovolaemic shock in women with post-partum haemorrhage.

One of the most relevant trials by HRP in the area of maternal and perinatal health is the multicentre trial conducted to test the effectiveness of an evidence-based antenatal care model based on four prenatal visits and one post-partum visit. The trial, published in 1995, showed that this model was as effective as standard regimes in terms of major pregnancy outcomes, acceptability and cost. The results of the study have been widely utilized in many countries as the basis for guidance on antenatal care at a national level; they were also instrumental in the establishment of indicators to monitor access to appropriate antenatal care at both national and international levels [146].

More recently, HRP expanded the focus on antenatal care to address critical issues of implementation of the four prenatal plus one post-partum visit model and of access to care by conducting ongoing implementation research studies in Tanzania and Mozambique aimed at increasing community participation in antenatal care and at addressing the limitations of the health system in equipping antenatal care clinics with the needed supplies to administer all prescribed tests and interventions.

Research efforts by HRP are aimed not only at informing clinical practice but also at positively influencing policies to improve women's and children's health. Fighting the dangerous practice of FGM and monitoring the recourse to CS offer two illustrative examples. 
As already mentioned, FGM represents a type of violence perpetrated against young girls through a harmful culturally rooted practice which still affects millions of them around the world. To support efforts at national and international levels to ban the practice of FGM, HRP conducted a multicentre study to provide previously lacking evidence on the negative consequences of FGM on pregnancy outcome. The study, published in 2006, showed that women with FGM were significantly more at risk of adverse obstetric outcomes and that the risk was higher with more extensive FGM. These important results contributed to increase the support base for the statement described earlier aimed at eliminating FGM that has been signed by 10 UN agencies and was published in 2008 [147].

HRP has also gathered evidence documenting the steady increase in CS rates over the last few decades. This trend has become a major public health concern and a cause of considerable polarized debate even at the political level. Recent figures show that most of the middleand high-income countries exceed the 1985 WHO-proposed standard rate of $15 \%$, with many countries now exceeding 30\% CS rates. As for many other aspects of health, these high rates contrast sharply with the very low rates in numerous low-income countries, particularly in Africa, which reflect unacceptable limitations in access to basic obstetric services [148]. The effort in monitoring rates worldwide was accompanied by studies aimed at documenting through a global survey the potential negative consequences of an excessive and unjustified use of CS. Evidence collected from Latin America and Asia demonstrates that increased rates of potentially non-necessary CS are associated with higher maternal and perinatal risks. The low rates typical of many African contexts reflect inadequate access to needed emergency obstetrical care and put women at a higher risk of poor obstetrical outcomes $[149,150]$. Recognizing that the rising trend is unprecedented and driven by multiple determinants, HRP has recently conducted additional research to evaluate the medical, sociocultural, anthropologic and financial factors associated with the increased use of CS [151-153].

As HRP's focus on maternal and perinatal health keeps expanding, more emphasis is placed on implementation science and innovation in an effort to develop strategies and products to make services more accessible to larger populations. Examples of ongoing and planned research include innovative strategies to improve the supply chain of commodities, development of international standards for foetal growth monitoring and assessment, identification of genetic and biological markers of pre-

The Special Programme of Research in Human Reproduction term birth, development of mobile phone aids for diagnosis and referral, and portable diagnostic devices and a new low-cost instrument for assisted vaginal delivery.

\section{(5) Prevention and Treatment of STIs and of Their Consequences}

STIs and RTIs are responsible for considerable ill health throughout the world, both directly and by increasing the risk of transmission of HIV infection and the ensuing AIDS. Each year, there are an estimated 449 million new cases of curable STIs, as well as many millions of incurable viral STIs, including some 2.7 million new HIV infections. In the 1980s, the prevention and treatment of STIs was identified as one approach to controlling the HIV epidemic. As antiretroviral (ARV) treatment of people with HIV/AIDS acquires a higher profile, it is important not to lose sight of the continuing need for prevention, of which STI and RTI control is a key component. In addition, SRH services offer an opportunity to provide counselling and advice on HIV prevention.

HRP's work in this area has focused on developing chemical and mechanical barriers to STI transmission, testing the safety and effectiveness of highly active ARV therapy in preventing mother-to-child transmission of HIV (PMTCT), improving understanding of the epidemiology of STIs and RTIs, and testing strategies for the introduction of new technologies. Some examples are provided below.

\section{Prevention of Mother-to-Child Transmission of HIV}

After a comprehensive review of outstanding knowledge gaps in the science of PMTCT, the Programme started work on the so-called Kesho Bora project (meaning 'a better future' in Swahili) in 2000 [154-163]. The main objective of the project was to assess the safety and efficacy of a triple-ARV regimen taken during late pregnancy, delivery and the breastfeeding period, to reduce the risk of HIV transmission particularly during breastfeeding. The trial compared a triple regimen consisting of zidovudine (AZT), lamivudine (3TC), and lopinavir/ritonavir (LPV/r) taken late in pregnancy and continued during breastfeeding up to a maximum of 6.5 months post-partum (the 'triple-ARV' prophylaxis), to the administration of AZT until delivery, followed by a single dose of nevirapine (sd-NVP) at the onset of labour and, from December 2006, the administration for 1 week postpartum of AZT/3TC (the 'AZT/sdNVP' prophylaxis). It 
was expected that, if successful, the project would lead to important changes in breastfeeding practices by women with HIV infection in resource-limited settings. The project was also intended to give more attention to the health of the mother with HIV infection and to better understand how to balance her health and long-term survival with the health and survival of her baby.

The cumulative risk of HIV-1 transmission at 12 months was $5.4 \%$ in the triple-ARV arm and $9.5 \%$ in the AZT/sdNVP arm $(\mathrm{p}=0.029)$, i.e. a $43 \%$ risk reduction, with a similar incidence of laboratory and clinical serious adverse events in the two groups. The preventive efficacy was much greater for women with CD4+ cell counts in the range of 200-350 cells $/ \mathrm{mm}^{3}$ than in those with CD4+ cell counts in the range of $350-500$ cells $/ \mathrm{mm}^{3}$. Among women with CD4+ cell counts above 500 cells $/ \mathrm{mm}^{3}$ (who all received the AZT/sdNVP regimen in an open-label prospective cohort) post-natal transmissions occurred at infant ages between 6 weeks and 6 months. These results emphasize the importance of providing early ARV therapy to all pregnant women with CD4+ cell counts below 350 cells $/ \mathrm{mm}^{3}$, as recommended in WHO 2010 ARV therapy guidelines [164]. It is in this group that nearly $90 \%$ of transmissions occurred, and universal coverage of ARV therapy for eligible women has the potential to prevent up to $90 \%$ of MTCT while preserving the health of the mothers. Obtaining an undetectable viral load by the time of delivery and sustaining it during breastfeeding is clearly the goal of maternal ARV prophylaxis. At least 8 weeks of prophylaxis were needed before an undetectable viral load was achieved in a minimum of $75 \%$ of women in the Kesho Bora study.

Data from the Kesho Bora trial have had a strong influence in shaping the revised $\mathrm{WHO}$ recommendations on the use of ARV drugs for the prevention of MTCT. The fact that extended use of ARV prophylaxis during breastfeeding had been shown to be safe and effective led experts to recommend a longer duration of breastfeeding. It was anticipated that this will avoid many of the malnutrition and other morbidities associated with complete cessation of all breastfeeding before 6 months of age. The efficacy of the new ARV-based strategy also led UNAIDS, WHO, UNICEF, the Global Fund to Fight AIDS, Tuberculosis and Malaria, and partner agencies to launch an 'MTCT elimination' initiative.

Progress in fighting the HIV/AIDS pandemic continues, and in 2010 some $35 \%$ of the estimated 123 million pregnant women in low- and middle-income countries received an HIV test, up from $26 \%$ in $2009,21 \%$ in 2008 and $8 \%$ in 2005 [165].
Strategy for the Elimination of Congenital Syphilis

Congenital syphilis (CoSy) is a serious, but preventable, disease which could be eliminated through effective screening of pregnant women for syphilis and treatment of those infected. However, services are lacking in many parts of the world. The Programme conducted case studies in Bolivia, Kenya and South Africa to document the operational difficulties met by their antenatal syphilis control programme [166]. This research documented that early antenatal syphilis screening and management of positive cases were difficult to implement since most women presented for their first antenatal clinic visit after 6 months of pregnancy. Most women had the so-called rapid plasma reagin (RPR) testing (based on the identification of nonspecific antibodies that may indicate the presence of the Treponema pallidum), but results were available on the same day in some clinics, whereas it took up to 4 weeks in others. No clinic had a system for tracking RPR-reactive women who did not return for their results. There were no guidelines for providers in Kenya and Bolivia. In all countries, supplies, drugs, notification cards, and other consumables were often unavailable. Some health care providers were not aware that CoSy still existed and some feared injecting penicillin into pregnant women. In South Africa and Kenya some clients reported at their exit interview that they had never heard of syphilis and that they had not been informed of why blood was collected.

These data suggested a number of prevention strategies: encourage women to attend clinics for antenatal care before the fourth month of pregnancy, provide point-of-care testing so that results become available immediately and women who test positive can be treated, implement presumptive treatment of sexual partners of women who test positive, add a second test later in pregnancy so that incident cases can be managed, and improve the quality of syphilis care during pregnancy, delivery, and the neonatal period.

As a follow-up, the Programme supported a cluster randomized trial in Mongolia to test whether a one-stop service could better prevent CoSy compared to the conventional antenatal screening service. The results showed that, in this setting, one-stop services increased the detection rate of syphilis, treated more positive women and their partners, and effectively reduced the rate of CoSy $[167,168]$.

Together with partners, the Programme supported the introduction of rapid tests in the CoSy programmes of Bolivia and Madagascar. These country experiences demonstrated the need for strengthening surveillance systems and also highlighted the benefits of dual HIVsyphilis rapid tests. 
This experience, together with the establishment of a global monitoring and evaluation system and evidence gathered by partners, was used to develop the initiative 'The global elimination of congenital syphilis: rationale and strategy for action' launched by the WHO in 2007 [169].

Subsequent cost-benefit analyses and modelling work led to the formulation of an investment case for countries, soon to be published.

Current work undertaken by the Programme focuses on integrating CoSy services with other SRH services, such as PMTCT services. As an example, in Zambia a field assessment of dual HIV-syphilis test performance is being conducted in the context of dual elimination of vertical transmission of HIV and syphilis, and service delivery packages for 'test and treat' strategies to integrate syphilis into current PMTCT programming are being assessed.

\section{Screening for Cancer of the Cervix in Developing Countries}

Cancer of the cervix is the second most common cancer in women, with about 500,000 new cases and 250,000 deaths each year. Almost $80 \%$ of cases occur in low-income countries, where it is the most common cancer in women. One of the main challenges is to make screening and diagnostic methods available widely in low-resource settings. Thus the Programme launched a demonstration project to assess the acceptability and feasibility of implementing a cervical cancer prevention programme based on the 'screen and treat' approach, using visual inspection after applying acetic acid (VIA) and cryotherapy in 6 countries (Madagascar, Malawi, Nigeria, Uganda, United Republic of Tanzania and Zambia). Of the 19,500 women screened, $10.1 \%$ were VIA positive and, of those eligible for cryotherapy, $61.4 \%$ received treatment; a further $28.7 \%$ were on the waiting list and $9.9 \%$ were lost to follow-up. The procedure was found to be highly acceptable to women. Scaling-up difficulties and impediments included the development of national plans and guidelines, supervision, breakdown of cryotherapy equipment, monitoring and evaluation, and training of health care workers in VIA and cryotherapy [170].

Based on these results, and on the initiative, the Ministries of Health of these 6 countries started to scale-up the activity and develop national cervical cancer prevention and control plans. Evidence generated by this study is also being used to update RHR guidance 'Comprehensive cervical cancer control - guidelines to essential practice' [171-173].

The Special Programme of Research in Human Reproduction

\section{(6) Adolescent SRH}

\section{Formative Research}

In 1998, within the social science research programme (see below) HRP focused its attention on the SRH needs of adolescents, aimed at identifying determinants of positive SRH outcomes. In the context of this research initiative, 54 studies have been conducted in 28 countries investigating a wide range of issues including safe and wanted sex, unwanted pregnancy and its consequences, gender roles and sexual attitudes, health-seeking behaviours, quality of care and providers' views.

Common to most studies is the application of a core set of research instruments, including a survey questionnaire, focus group discussion and in-depth interview field guidelines adaptable to cultural settings, and research questions.

In 2009, data from 17 of the sponsored studies were analysed in a systematic review of risk-taking behaviours among adolescents. The review highlighted that information on prevention of STIs and pregnancy among adolescents is low, misperception of risk is common and access to contraception is limited. The findings of the systematic review are of critical importance to inform policies aimed at improving the SRH of adolescents [174].

\section{(7) Men's SRH}

When the Programme started its activities, contraceptive methods for men had received disproportionately little attention and efforts to develop methods that would interfere with sperm formation had proven unsuccessful because of undesirable side effects, particularly on the libido. For this reason, work on contraception for men was included in the original plan of action of HRP. Special attention was devoted to hormonal methods, commonly known as 'male pills', and by 1980 HRP-sponsored clinical studies had shown that the administration over 1 year of $500 \mu \mathrm{g}$ daily of LNG and $200 \mathrm{mg}$ monthly of testosterone enanthate (TE) significantly decreased the sperm count without any significant effect on potency or the libido [175]. Further studies with a combination of DMPA and TE produced similar results [176]. Unfortunately, in the late 1970s the Scientific Advisory Group of HRP decided that male methods were not a priority and activities were slowed down. When, in the mid-1980s, the climate changed, HRP immediately jumped back into action. It is HRP that has proven, once and for all, that an effective 'male pill' can be developed, although instead it may be a

Gynecol Obstet Invest 2012;74:190-217 
'male jab'. In other words, HRP did for men what Gregory Pincus did for women.

Unfortunately, in practical terms, the development of a hormonal contraceptive for men proved to be much more complex and - to this day - no method has reached the stage of large clinical experimentation, as proven by the most recent research activities in this area; in 2008, in collaboration with CONRAD, the Programme started a safety and contraceptive efficacy trial of NET-EN combined with testosterone undecanoate for male contraception. In 2011, however, the study had to be terminated due to mood-related serious adverse events. Nonetheless, while the data collected are presently being analysed, preliminary results encourage the continued pursuit of new hormonal treatment for male contraception.

There are many other achievements in the field of male fertility regulation that should be mentioned: research conducted by the Programme produced data capable of reassuring men living in many countries in the developing world that vasectomy does not increase the likelihood of contracting cardiovascular diseases or prostate cancer [177]; in addition, HRP helped make the Chinese invention named 'no-scalpel vasectomy' a familiar technique all over the world [178]. HRP even won a film award on a documentary showing how this is performed [48].

The WHO Laboratory Manual for the Examination

of Human Semen and Sperm-Cervical Mucus

Interaction

This manual was first published in 1980 in response to an increased need for the standardization of procedures for the examination of human semen. Since that time, it has been updated three times and translated into a number of languages. The manual provides global standards for both research and clinical laboratories throughout the world.

The fifth edition is divided into three parts: semen analysis, sperm preparation, and quality assurance [179].

\section{Men's Role in Women's SRH}

Studying SRH, it is important to recognize the role of men in decision-making by a couple, as well as their behaviour in relation to their own and their partners' health. In 2011, HRP collaborated with the WHO HIV/AIDS department to publish guidelines for the prevention and treatment of HIV and other STIs among men who have sex with men and transgender people. In this manual, the Organization made a strong case for a public health approach to this issue [180]. The guidelines provide evidence-based information on a package of interventions for the prevention and treatment of HIV and STIs in specific male populations.

Other activities focusing on men and HIV/AIDS include work on males' involvement in PMTCT, genderbased violence in the context of HIV and male circumcision as a preventive strategy.

\section{(8) Promotion of Sexual Health and Reproductive Rights}

As already mentioned, the 1994 ICPD and the subsequent 1995 WCW defined reproductive health as incorporating sexual health. However, recently this conceptualization has changed, with the recognition that sexual health is, in fact, broader and more encompassing than reproductive health and is relevant throughout the life span and not only during the reproductive years.

If they are to achieve $\mathrm{SRH}$, people must be empowered to exercise control over their sexual and reproductive lives and must have access to related health services. While these rights, and the ability to exercise them, constitute an important value in themselves, they are also a condition for well-being and development.

Discrimination against girls and women often places them at a disadvantage in terms of decision-making power, choices and opportunities. In some countries, the low level of control that young women have over their lives has critical consequences for their sexual health. They may be under severe pressure to marry early, begin childbearing immediately, and engage in sexual activity as a marital obligation. It is thus clear that issues of gender inequality and reproductive rights are inextricably intertwined with SRH.

\section{Devise Tools for Operationalizing a Human Rights}

Approach to SRH Programmes and Services

In response to the WHO GRHS of 2004 calling for the establishment of supportive legislative and regulatory frameworks for the achievement of the MDGs and targets, particularly universal access to reproductive health, HRP in collaboration with the Programme on International Health and Human Rights at the Harvard University School of Public Health, Boston, Mass., USA, developed a tool that provides a method for countries to use a human rights framework to identify and address legal, policy and regulatory barriers to people's access to SRH and to the provision of quality services.

In its first version, the tool, entitled 'Using human rights for maternal and neonatal health: a tool for 
strengthening laws, policies and standards of care', focused on maternal and newborn care [181]. In 2004-2005, field tests of the tool were launched in Brazil, Indonesia and Mozambique. As an example, in Mozambique it was found that, although the government had made significant progress in reducing maternal and neonatal mortality, coverage of antenatal care services was still limited and patchy. Pregnant women were often not screened for CoSy, a leading cause of death among newborn infants. In addition, because of logistic and organizational issues, the essential medicines package did not include a number of potentially life-saving drugs, such as oxytocics. These findings were used to set priorities for focusing resources in the following years and to change policies to help resolve some of the problems.

As a result of the evaluation of the field tests at the end of 2006, the tool was revised to focus on the five core components of SRH as outlined in the WHO GRHS [182, 183]. The tool brings together information about which human rights treaties - both international and regional - a country has ratified and, for each core component, covers cross-cutting human rights principles such as: non-discrimination and recognition of vulnerable groups; availability, accessibility, acceptability and quality of SRH services and access to information, and informed consent.

A companion tool was also developed to focus specifically on adolescents' SRH. Its section on maternal health, for instance, focuses more specifically on early marriage and early childbearing.

Using the tool helps countries to: recognize national human rights obligations related to $\mathrm{SRH}$; review and document government efforts to put in place a supportive legal and policy framework related to SRH; identify legal, policy and regulatory barriers to achieving SRH for all, and make recommendations to overcome or reduce these barriers; identify especially vulnerable groups and existing government effort to address their needs, and engage the health sector as well as non-health sector actors to help eliminate legal, regulatory and policy barriers to SRH.

The tool application consists of a process which engages many different stakeholders. It involves compiling data from readily available sources on both health and legal aspects of SRH and analysing these data drawing on a human rights framework. On the basis of this analysis, the stakeholders generate recommendations, and assign responsibilities, for action. The ultimate aim is to ensure a positive, enabling environment to foster the enjoyment of rights, in support of the achievement of SRH.

The Special Programme of Research in Human Reproduction
The human rights tool for SRH and its adaptation to adolescents' SRH was developed, field tested and applied in the Republic of Moldova, Sri Lanka and Tajikistan.

They are now being applied in collaboration with various government ministries, other UN agencies such as UNAIDS, UNFPA, and UNICEF, and international and national NGOs and donor agencies.

\section{Evaluate the Impact of Violence against Women}

In 2003 Kofi Annan, then Secretary-General of the $\mathrm{UN}$, decried in a strong statement violence against women as an 'atrocious manifestation of continued systematic discrimination and inequality' [184]. It is for this reason that the WHO decided that policies to prevent violence against women should be implemented at three major levels, i.e. the family, the community and the state, and should be part of the agenda for equality, development, public health, and human rights [185]. Men's violent behaviours are often expressed within the family where girls and women are vulnerable to infanticide, genital mutilation, a child's marriage without her consent, dowry-related violence, battering and sexual abuse [186].

To positively address violence within intimate partners (IPV), the WHO has conducted a series of standardized, population-based surveys to determine the extent of the occurrence of episodes of physical and sexual abuse of women by a current or former intimate male partner. This multicentre, multinational study represents the first global effort to gather reliable and comparable data on domestic violence and its effect on the health of women. The work was carried out in partnership with women's organizations; this approach was invaluable in the collection of evidence and helped strengthen national efforts to address violence against women [187].

The study, conducted in 10 countries, involved around 1,500 interviews per site, reporting a lifetime prevalence of physical or sexual partner violence, or both, ranging between 15 and $71 \%$. In general, the perpetrator of violence was more often the woman's own partner than other people [188].

When data collected were pooled, a significant association emerged between experiencing IPV and self-reported poor health, ranging from difficulty in walking and carrying out daily activities to pain, loss of memory, dizziness and vaginal discharge. In addition, victims of IPV reported significantly more emotional distress and suicidal thoughts and attempts [189]. Finally, women with a history of IPV had significantly higher odds of unintended pregnancy (8 of 14 sites) and of abortion (12 of 15 sites), after adjusting for confounding factors. This led 
to the conclusion that reducing IPV by $50 \%$ could potentially reduce unintended pregnancy by $2-18 \%$ and abortion by $4.5-40 \%$, according to population-attributable risk estimates [190].

\section{(9) SRH Programmes and Services}

\section{Social Science and Operations Research}

Following up the already mentioned work on acceptability of family planning methods, in 1985 HRP established a Task Force on Social Science Research with the scope of improving the quality and availability of and demand for health care services. Initially, work concentrated in the area of fertility regulation, but in 1990 the scope of the group was expanded to three new areas: (a) sexual behaviour and reproductive health, (b) social dimension of maternal health, and (c) breastfeeding and birth-spacing.

In particular, the Programme began to address a major concern for many national family planning programmes: poor continuation rates of modern methods and an incomplete understanding of the role of contraception in human reproductive behaviour. As a consequence, the role of communities in facilitating or impeding access to methods, the changing status of women and the costs and benefits of contraception emerged as main research priorities [6].

Among the unique type of research launched and successfully completed in over 30 developing countries is the study of the determinants and consequences of induced abortions [191]. This initiative provoked debate in parliaments and led to the creation of better services and to calls for decriminalization as a life-saving measure.

By the year 2000, HRP was fully involved in research on users' perspectives of reproductive health technologies and services, covering issues such as the perception by individual women and men of their reproductive health needs and risks, the acceptability of the options available to them, the obstacles they face both in protecting themselves from infection and in achieving their desired numbers of children safely and healthily, and their preferences for services.

In this connection, HRP participated in a major study dealing with contraceptive choice, continuation, and switching. Using data from the Demographic and Health Surveys in 15 developing countries, the study found that, overall, $36 \%$ of all users of reversible contraceptive methods discontinue use within the first year. Two in three users of the diaphragm, jelly or foam tab- lets discontinue their use in the first year, primarily because of method or user failure (20\%) or health concerns (16\%) [192].

More recently, two studies were launched with the aim of evaluating the impact on the health of users of programmes in which sexuality counselling has been integrated into SRH services and of services that have included the treatment of victims of domestic violence.

\section{Definition of Core Competencies in Primary Health Care}

In 2008, HRP received a strong mandate from its Advisory Committee to define core competencies, including clinical, management and counselling competencies for health care providers in SRH. The recommendation coincided with a renewed interest in the primary health care (PHC) approach, as this was the focus of the 2008 World Health Report [193]. Within this context, the objectives of strengthening the health systems capacity to deliver comprehensive services and increase access to care fostering universal coverage appeared to be central to both concepts of SRH and PHC. Therefore, HRP embarked on the process of developing guidance to assure that SRH workers would be proficient in the competencies required to provide $\mathrm{PHC}$.

The core SRH competencies that are desirable for use in $\mathrm{PCH}$ were collected together in a document reflecting the attitudes, tasks, knowledge, and skills that health personnel in PHC may need, to protect, promote and provide SRH in the community [194]. These competencies define the basis of the education/training requirements and the service-delivery capacity needed to provide safe quality SRH care.

Provide Summaries of Research Results and Translate the Evidence in Terms of Clinical Practice

In the 1990s and early 2000s, HRP actively engaged with international partners in several activities aimed at synthesizing evidence, while continuing to generate new scientific evidence trough clinical trials. A very successful collaboration with the Cochrane Library led to the establishment of the WHO Reproductive Health Library (RHL). Originally established in 1998 as a compilation of Cochrane reviews focusing on reproductive health, RHL is now an electronic review journal providing, in addition to Cochrane reviews, the following services:

- independent expert commentaries on single or a collection of related Cochrane reviews;

- practical advice on implementation of findings of each Cochrane review; 
- a complete list of interventions evaluated in RHL, classified by the degree of their effectiveness;

- a set of training videos to help clinicians master details of manual and surgical procedures;

- a set of published journal articles and other materials to help understand and practice evidence-based SRH. Most of the work conducted by HRP in research synthesis is aimed at informing the production of guidelines through a well-defined system implemented across all WHO departments by the Guideline Review Committee and established after a report published in Lancet in 2007 highlighted that WHO guidelines relied mostly on expert opinion and only seldom were based on evidence provided by systematic review [195].

Clinical and health policy guidelines represent one of the major outputs of HRP, and several mechanisms have been put in place to assure that guidelines are responsive to knowledge needs at the country level and get constantly updated to reflect new evidence as it gets published. Examples of such mechanisms are the GREAT (Guideline development, Research priorities, Evidence synthesis, Applicability of evidence, Transfer of knowledge) project for maternal and perinatal health and the CIRE system for family planning $[196,197]$.

\section{(10) Global Monitoring and Evaluation}

In the 2000s the need to track the progress of major initiatives such as the MDG Declaration, the Reproductive Health Strategy approved by the World Health Assembly in 2004, and the Global Strategy for Women's and Children's Health made monitoring of SRH indicators at the global level a priority for HRP. Therefore, the Programme established a collaborative process to calculate global estimates for important maternal and perinatal health indicators. Over time, the methods applied improved significantly and the progressive engagement of more academic institutions ensured transparency of the process. Countries were actively engaged in the estimation process of relevant and potentially controversial indicators, such as maternal mortality, and in improving the understanding, acceptability and ownership of the data at the country level. The process expanded into a framework to monitor universal access to reproductive health allowing for constant updates of estimates, revision of methodology and comparison of temporal trends.

In terms of methodological improvements, major achievements included the standardization of reproduc- tive health indicators with important implications for the revision of the International Classification of Disease (ICD) [198] and the development of a standard definition of maternal near miss which could be used as an indicator of quality of care at the health system level [199].

Significant results in methodological improvements have been documented by landmark and widely cited publications of estimates of maternal mortality rates and causes of deaths, as well as of estimates of important perinatal indicators such as stillbirths and rates of pre-term birth [200-205]. HRP has also contributed to the development of the Countdown to 2015 reports since 2008.

\section{Looking towards the Future}

Building on 40 years of success, sustained financial support, and international recognition, HRP is looking toward the future with confidence and enthusiasm. The expansion of its support base within the UN system and the donor community is affirmation of the Programme's continued high standing and relevance. Renewed global interest in family planning and innovative technologies as central to overall development and to the achievement of the MDGs is also a promising climate for the short- and long-term work plans of HRP.

This article has taken stock of the history and vision of the Programme and reviewed major contributions of HRP in the field of SRH, starting in 1972 with the establishment of task forces to develop contraceptive methods that would help foster development, better health, and the fulfilment of basic human rights. Given the magnitude of the work carried out by the Programme, it was inevitable to leave out of this review a number of important achievements by HRP, such as the study alerting the world of an increased risk of thromboembolic events in women using third- versus second-generation progestins. Nonetheless, we hope to have provided a global picture of the fields covered by HRP's research and the fact that the Programme's focus has expanded over the years to include all dimensions of SRH.

In spite of formidable evolution, the original underlying humanitarian orientation and scientific spirit remain untouched and are stronger than ever. It is a testament to the strength of the Programme that this spirit, in addition to an emphasis on collaboration, has continued for four decades.

Gynecol Obstet Invest 2012;74:190-217 


\section{References}

1 Kessler A: Establishment and early developments of the programme; in Khanna J, Van Look PFA, Griffin PD (eds): Reproductive Health: A Key to a Brighter Future - Biennial Report for 1990-1991 of the Special Programme of Research, Development, and Research Training in Human Reproduction. Geneva, WHO, 1992.

2 World Health Organization, Regional Office for South-East Asia: Final report on pilot studies in family planning. New Delhi, WHO, 1954, vol I and II.

3 Work of the Fifth World Health Assembly: population problems. Chron World Health Organ 1952;6:183-184.

4 Litsios S: The Third Ten Years of the World Health Organization, 1968-1977. Geneva, WHO, 2008, pp 94-95.

5 WHO Expanded Programme of Research, Development and Research Training in $\mathrm{Hu}$ man Reproduction: First annual report. Geneva, WHO, 1973.

-6 Diczfalusy E: World Health Organization. Special Programme of Research, Development and Research Training in Human Reproduction. The first fifteen years: a review. Contraception 1986;34:3-119.

7 Fathalla MF: Reproductive health in the world: two decades of progress and the challenge ahead; in Khanna J, Van Look PFA, Griffin PD (eds): Reproductive Health: A Key to a Brighter Future - Biennial Report for 1990-1991 of the Special Programme of Research, Development, and Research Training in Human Reproduction. Geneva, WHO, 1992.

>8 Skakkebaek NE, Negro-Vilar A, Michal F, Fathalla MF: Impact of the environment on reproductive health: report and recommendations of a WHO international workshop. Danish Med Bull 1991;38:425-426.

$\checkmark 9$ Gakidou E, Vayena E: Use of modern contraception by the poor is falling behind. PLoS Med 2007;4:e31.

10 Gonzales R, Requejo JH, Nien JK, Merialdi M, Betran AP, Chile Maternal, Newborn and Child Writing Group: Tackling health inequities in Chile: maternal, newborn, and child mortality between 1990 and 2004. Am J Public Health 2009;99:1220-1226.

11 United Nations, Department of Economic and Social Affairs, Population Division: World population prospects: the 2010 revision. New York, UN, 2011.

12 United Nations Population Information Network (POPIN), UN Population Division, Department of Economic and Social Affairs, with support from the UN Population Fund (UNFPA): Report of the International Conference on Population and Development (Cairo, 5-13 September 1994). Document A/ CONF.171/13: report of the ICPD (94/10/18). New York, UN, 1994.
13 World Health Organization: Reproductive health strategy to accelerate progress towards the attainment of international development goals and targets: global strategy adopted by the 57th World Health Assembly. Geneva, WHO, 2004, p 36.

14 World Health Organization: Global strategy for the prevention and control of sexually transmitted infections: 2006-2015 - breaking the chain of transmission. Geneva, WHO, 2007, pp 61.

15 United Nations: Report of the SecretaryGeneral on the work of the Organization: official records of the General Assembly, sixtyfirst session, suppl 1 (A/61/1). New York, UN, 2006.

16 Lawn JE, Cousens S, Zupan J, Lancet Neonatal Survival Steering Team: 4 million neonatal deaths: when? Where? Why? Lancet 2005; 365:891-900.

17 Ronsmans C, Graham WJ, Lancet Maternal Survival Series steering group: Maternal mortality: who, when, where, and why. Lancet 2006;368:1189-1200.

18 Black RE, Morris SS, Bryce J: Where and why are 10 million children dying every year? Lancet 2003;361:2226-2234.

19 Ban K: Global Strategy for Women's and Children's Health. http://www.who.int/ pmnch/activities/jointactionplan/en/.

20 UNAIDS, UNDP, UNECA, UNESCO, UNFPA, UNHCHR, UNHCR, UNICEF, UNIFEM, WHO: Eliminating female genital mutilation: an interagency statement. Geneva, WHO, 2008.

21 UNFPA, UNHCR, UNICEF, UNIFEM, WHO, FIGO, ICN, MWIA, WCPA, WMA: Global strategy to stop health-care providers from performing female genital mutilation. Geneva, WHO, 2010.

22 World Health Organization, Department of Reproductive Health and Research: Preventing gender-biased sex selection: an interagency statement - OHCHR, UNFPA, UNICEF, UN Women and WHO. Geneva, WHO, 2011.

23 van der Poel SZ: Historical walk: the HRP Special Programme and infertility. Gynecol Obstet Invest 2012;74:218-227.

24 World Health Organization, Task Force on Methods for the Determination of the Fertile Period: Temporal relationships between ovulation and defined changes in the concentration of plasma estradiol-17 $\beta$, luteinizing hormone, follicle-stimulating hormone, and progesterone. 1. Probit analysis. Am J Obstet Gynecol 1980;138:383-389.

25 World Health Organization, Task Force on Methods for the Determination of the Fertile Period: Temporal relationships between ovulation and defined changes in the concentration of plasma estradiol-17 $\beta$, luteinizing hormone, follicle-stimulating hormone, and progesterone. 2. Histologic dating. Am J Obstet Gynecol 1981;139:886-895.
26 World Health Organization, Task Force on Methods for the Determination of the Fertile Period: Temporal relationships between indices of the fertile period. Fertil Steril 1982; 39:647-655.

27 World Health Organization, Task Force on Methods for the Determination of the Fertile Period: A prospective multicentre trial of the ovulation method of natural family planning. 1. The teaching phase. Fertil Steril 1981;36:152-158.

28 World Health Organization, Task Force on Methods for the Determination of the Fertile Period: A prospective multicentre trial of the ovulation method of natural family planning. 2. The effectiveness phase. Fertil Steril 1981;36:591-598.

29 World Health Organization, Task Force on Methods for the Determination of the Fertile Period: A prospective multicentre trial of the ovulation method of natural family planning. 3. Characteristics of the menstrual cycle and of the fertile phase. Fertil Steril 1983; 40:773-778.

30 World Health Organization, Task Force on Methods for the Determination of the Fertile Period: A prospective multicentre trial of the ovulation method of natural family planning. 4. The outcome of pregnancy. Fertil Steril 1984;41:593-598.

31 World Health Organization, Task Force on Methods for the Determination of the Fertile Period: The ovulation method of natural family planning. Bull World Health Organ 1985;63:44-46.

32 Singh H, Saxena BB, Rathnam P: Clinical validation of enzyme-immunoassay of human luteinizing hormone (hLH) in the detection of the preovulatory luteinizing hormone (LH) surge in urine. Fertil Steril 1984; 41:210-217.

33 World Health Organization, Task Force on Methods for the Determination of the Fertile Period: The measurement of urinary steroid glucuronides as indices of the fertile period in women. J Steroid Biochem 1982;17:695702.

34 Schiphorst LE, Collins WP, Royston, JP: An estrogen test to determine the times of potential fertility in women. Fertil Steril 1985; 44:328-334.

35 Labbok M: Breastfeeding and contraception. N Engl J Med 1983;308:351.

36 World Health Organization, Task Force on Methods for the Natural Regulation of Fertility: The World Health Organization multinational study of breast-feeding and lactational amenorrhea. 1. Description of infant feeding patterns and of the return of menses. Fertil Steril 1998;70:448-460. 
37 World Health Organization, Task Force on Methods for the Natural Regulation of Fertility: The World Health Organization multinational study of breast-feeding and lactational amenorrhea. 2. Factors associated with the length of amenorrhea. Fertil Steril 1998; 70:461-471.

- 38 World Health Organization, Task Force on Methods for the Natural Regulation of Fertility: The World Health Organization multinational study of breast-feeding and lactational amenorrhea. 3. Pregnancy during breast-feeding. Fertil Steril 1999;72:431440.

39 World Health Organization, Task Force on Methods for the Natural Regulation of Fertility: The World Health Organization multinational study of breast-feeding and lactational amenorrhea. 4. Postpartum bleeding and lochia in breast-feeding women. Fertil Steril 1999;72:441-447.

-40 Fajans P, Simmons R, Ghiron L: Helping public sector health systems innovate: the strategic approach to strengthening reproductive health policies and programs. Am J Public Health 2006;96:435-440.

-41 Benagiano G, Fraser I: The Depo-provera debate: commentary on the article 'Depo-Provera, a critical analysis'. Contraception 1981; 24:493-528.

42 Finkel NC, Berliner VR: The extrapolation of experimental findings (animal to man): the dilemma of systematically administered contraceptives. International Academy of Pathology, 62nd Annual Meeting, Washington, 1973.

$\checkmark 43$ World Health Organization: Multinational comparative clinical evaluation of two longacting injectable contraceptive steroids: norethisterone oenanthate and medroxyprogesterone acetate. 1. Use-effectiveness. Contraception 1977;15:513-533.

44 World Health Organization: Multinational comparative clinical evaluation of two longacting injectable contraceptive steroids: norethisterone oenanthate and medroxyprogesterone acetate. 2. Bleeding patterns and side effects. Contraception 1978;17:395-406.

$\checkmark 45$ World Health Organization: Multinational comparative clinical evaluation of two longacting injectable contraceptive steroids: norethisterone oenanthate given in two dosage regimens and depot-medroxyprogesterone acetate - a preliminary report. Contraception 1982;25:1-11.

-46 World Health Organization: Multinational comparative clinical evaluation of two longacting injectable contraceptive steroids: norethisterone oenanthate given in two dosage regimens and depot-medroxyprogesterone acetate - final report. Contraception 1983; 28:1-20.

$\checkmark 47$ World Health Organization: Facts about injectable contraceptives. Bull World Health Organ 1982;60:199-210.
48 Kovács L, Resch BA (eds): Research on Human Reproduction: 25 Years of Achievement with the WHO Special Programme of Research, Development and Research Training in Human Reproduction - A Symposium to Celebrate the 25th Anniversary of WHOHRP and Its Collaborating Centres, 13-14 October, 1997, Szeged, Hungary. Szeged, Albert Szent-Gyorgyi Medical University Press, 1998.

49 Benagiano G, Diczfalusy E, Goldzieher JW, et al: Multinational comparative clinical evaluation of two long-acting injectable contraceptive steroids: norethisterone oenanthate and medroxyprogesterone acetate. 1 . Use-effectiveness. Contraception 1977;15: 513-533.

50 Benagiano G, Diczfalusy E, Diethelm P, et al: Multinational comparative clinical evolution of two long-acting injectable contraceptive steroids: norethisterone oenanthate and medroxyprogesterone acetate. 2. Bleeding patterns and side effects. Contraception 1978;17:395-406.

51 Crabbe P, Diczfalusy E, Djerassi C: Injectable contraceptive synthesis: an example of international cooperation. Science 1980;209:992994.

52 Crabbe P, Archer S, Benagiano G, Diczfalusy E, Djerassi C, Fried J, Higuchi T: Design of the WHO Chemical Synthesis Programme. Steroids 1983;41:243-254.

53 Steroids 1983;41:242-425.

54 World Health Organization, Special Programme of Research, Development and Research Training in Human Reproduction: Annual Technical Report 1996. Geneva, WHO, 1997, pp 41-43.

55 World Health Organization, Department of Reproductive Health and Research: Biennial Technical Report 2005-2006. Geneva, WHO, 2007, pp 32-33.

56 Garza-Flores J, Rodriguez V, Perez-Palacios $\mathrm{G}$, et al: A multicentre pharmacokinetic, pharmacodynamic study of once-a-month injectable contraceptives. 1. Different doses of HRP112 and DepoProvera. World Health Organization Task Force on Long-Acting Systemic Agents for Fertility Regulation. Contraception 1987;36:441-457.

57 Aedo AR, Landgren BM, Johannisson E, et al: Pharmacokinetic and pharmacodynamic investigations with monthly injectable contraceptive preparation. Contraception 1985; 31:453-469.

58 Fotherby K, Benagiano G, Toppoyada HK, et al: A preliminary pharmacological trial of the monthly injectable contraceptive, Cycloprovera. Contraception 1982;25:261-272.
59 Comparative Study of the effects of two once-a-month injectable steroidal contraceptives (Mesigyna and Cyclofem) on lipid and lipoprotein metabolism. United Nations Development Programme/United Nations Population Fund/World Health Organization/World Bank, Special Programme of Research, Development and Research Training in Human Reproduction. Contraception 1997;56:193-207.

60 Comparative Study of the effects of two once-a-month injectable steroidal contraceptives (Mesigyna and Cyclofem) on glucose metabolism and liver function. United Nations Development Program/United Population Fund/World Health Organization/ World Bank, Special Programme of Research, Development and Research Training in Human Reproduction, Task Force on Long-Acting Systemic Agents for Fertility Regulation. Contraception 1998;57:71-81.

61 United Nations Development Programme/ United Nations Population Fund/World Health Organization/World Bank Special Programme of Research, Development and Research Training in Human Reproduction, Task Force on Long-Acting Systemic Agents for Fertility Regulation: Comparative study of the effects of two once-a-month injectable contraceptives (Cyclofem and Mesigyna) and one oral contraceptive (Ortho-Novum $1 / 35$ ) on coagulation and fibrinolysis. Contraception 2003;68:159-176.

62 World Health Organization, Special Programme of Research, Development and Research Training in Human Reproduction, Task Force on Long-acting Systemic Agents for Fertility Regulation: A multicentred phase III comparative study of two hormonal contraceptive preparations given once-amonth by intra-muscular injection. 1. Contraceptive efficacy and side-effects. Contraception 1988;37:1-20.

- 63 World Health Organization, Special Programme of Research, Development and Research Training in Human Reproduction, Task Force on Long-acting Systemic Agents for Fertility Regulation: A multicentred phase III comparative study of two hormonal contraceptive preparations given once-amonth by intra-muscular injection. 2 . The comparison of bleeding patterns. Contraception 1989;40:531-551.

64 Sang GW, Shao QX, Ge RS, et al: A multicentred phase III comparative clinical trial of Mesigyna, Cyclofem and Injectable No. 1 given monthly by intramuscular injection to Chinese women. Contraception 1995;51: 167-183.

65 Sang GW, Shao QX, Ge RS, et al: A multicentred phase III comparative clinical trial of Mesigyna, Cyclofem and Injectable No. 1 given monthly by intramuscular injection to Chinese women. 2. The comparison of bleeding patterns. Contraception 1995;51:185192 
66 Hassan EO, El-Nahal N, El-Hussein M: Acceptability of the once-a-month injectable contraceptives Cyclofem and Mesigyna in Egypt. Contraception 1994;40:469-88.

- 67 Hassan EO, El-Nahal N, El-Hussein M: Once-a-month injectable contraceptives, Cyclofem and Mesigyna, in Egypt: efficacy, causes of discontinuation, and side effects. Contraception 1999;60:87-92.

68 Hall PE: The introduction of Cyclofem into national family planning programmes: experience from studies in Indonesia, Jamaica, Mexico, Thailand and Tunisia. Task Force on Research on Introduction and Transfer of Technologies for Fertility Regulation, Special Programme of Research, Development and Research Training in Human Reproduction, World Health Organization, Geneva, Switzerland. Contraception 1994;49:489507.

-69 Simmons R, Fajans P, Lubis F: Contraceptive introduction and the management of choice: the role of Cyclofem in Indonesia. Contraception 1994;49:509-525.

-70 Facts about an implantable contraceptive: memorandum from a WHO Meeting. Bull World Health Org 1985;63:485-494.

71 UNDP, UNFPA, WHO, World Bank, Special Programme of Research, Development and Research Training in Human Reproduction, Task Force on Long-Acting Systemic Agents for Fertility Regulation: Study of the effects of the implantable contraceptive Norplant on lipid and lipoprotein metabolism. Contraception 1999;59:31-45.

-72 Massai R, Pavez M, Fuentealba B, Croxatto $\mathrm{H}$, d'Arcangues $\mathrm{C}$ : Effect of intermittent treatment with mifepristone on bleeding patterns in Norplant implant users. Contraception 2004;70:47-54.

-73 d'Arcangues C, Piaggio G, Brache V, Aissa RB, Hazelden C, Massai R, Pinol A, Subakir SB, Su-juan G, Study Group on ProgestogenInduced Vaginal Bleeding Disturbances: Effectiveness and acceptability of vitamin $\mathrm{E}$ and low-dose aspirin, alone or in combination, on Norplant-induced prolonged bleeding. Contraception 2004;70:451-462.

-74 d'Arcangues C, Jackson E, Brache V, Piaggio G, Study Group on Progestogen-Induced Vaginal Bleeding Disturbances: Women's views and experiences of their vaginal bleeding patterns: an international perspective from Norplant users. Eur J Contracept Reprod Health Care 2011;16:9-17.

75 Thomas DB: The WHO Collaborative Study of Neoplasia and Steroid Contraceptives: the influence of combined oral contraceptives on risk of neoplasms in developing and developed countries. Contraception 1991;43: 695-710.

76 Epithelial ovarian cancer and combined oral contraceptives: the WHO Collaborative Study of Neoplasia and Steroid Contraceptives. Int J Epidemiol 1989;18:538-545.
Endometrial cancer and combined oral contraceptives: the WHO Collaborative Study of Neoplasia and Steroid Contraceptives. Int J Epidemiol 1988;17:263-269.

78 Breast cancer and combined oral contraceptives: results from a multinational study the WHO Collaborative Study of Neoplasia and Steroid Contraceptives. Br J Cancer, 1990;61:110-119.

79 Invasive squamous-cell cervical carcinoma and combined oral contraceptives: results from a multinational study - the WHO Collaborative Study of Neoplasia and Steroid Contraceptives. Int J Cancer 1993;55:228236.

80 Thomas DB, Ray RM: Oral contraceptives and invasive adenocarcinomas and adenosquamous carcinomas of the uterine cervix: the WHO Collaborative Study of Neoplasia and Steroid Contraceptives. Am J Epidemiol 1996;144:281-289.

81 Combined oral contraceptives and liver cancer: the WHO Collaborative Study of Neoplasia and Steroid Contraceptives. Int J Cancer 1989;43:254-259.

82 Combined oral contraceptives and gallbladder cancer: the WHO Collaborative Study of Neoplasia and Steroid Contraceptives. Int J Epidemiol 1989;18:309-314.

83 Breast cancer and depot-medroxyprogesterone acetate: a multinational study - the WHO Collaborative Study of Neoplasia and Steroid Contraceptives. Lancet 1991;338: 833-838.

84 Skegg DC, Noonan EA, Paul C, Spears GF, Meirik O, Thomas DB: Depot-medroxyprogesterone acetate and breast cancer: a pooled analysis of the World Health Organization and New Zealand studies. JAMA 1995;273: 799-804.

85 Depot-medroxyprogesterone acetate (DMPA) and risk of epithelial ovarian cancer: the WHO Collaborative Study of Neoplasia and Steroid Contraceptives. Int J Cancer 1991;49:191-105.

86 Depot-medroxyprogesterone acetate (DMPA) and risk of endometrial cancer: the WHO Collaborative Study of Neoplasia and Steroid Contraceptives. Int J Cancer 1991;49: 186-190.

87 Depot-medroxyprogesterone acetate (DMPA) and risk of invasive squamous cell cervical cancer: the WHO Collaborative Study of Neoplasia and Steroid Contraceptives. Contraception 1992;45:299-312.

88 Depot-medroxyprogesterone acetate (DMPA) and risk of liver cancer: the WHO Collaborative Study of Neoplasia and Steroid Contraceptives. Int J Cancer 1991;49:182185.

89 D'Arcangues C: Worldwide use of intrauterine devices for contraception. Contraception 2007;75(suppl 6):52-57.
90 The TCu 380A, TCu220C, multiload 250 and Nova T IUDs at 3, 5 and 7 years: results from three randomized multicenter trials. World Health Organization, Special Programme of Research, Development and Research Training in Human Reproduction and Task Force on Safety and Efficacy of Fertility-Regulating Methods. Contraception 1990;42:141-158.

91 Khanna J, Van Look PFA, Griffin PD (eds) Reproductive Health: A Key to a Brighter Future - Biennial Report for 1990-1991. Geneva, WHO, Special Programme of Research, Development and Research Training in Human Reproduction, 1992.

$\$ 2$ Long-term reversible contraception: twelve years of experience with the TCu380A and TCu220C. Contraception 1997;56:341-352.

93 A randomized, multicenter trial of the multiload 375 and $\mathrm{TCu} 380 \mathrm{~A}$ in parous women: three years results. UNDP/UNFPA/WHO/ World Bank, Special Programme of Research, Development and Research Training in Human Reproduction: IUD Research Group. Contraception 1994;49:543549.

94 World Health Organization, Department of Reproductive Health and Research: Annual Technical Report 2002. Geneva, WHO, 2003.

95 World Health Organization, Special Programme of Research in Human Reproduction: Highlights of 2005. Geneva, WHO, 2006.

96 Hoffman KO: Postcoital contraception: experiences with ethynilestradiol/norgestrel and levonorgestrel only; in Harrison RF, Bonnar J, Thompson W (eds): Proceedings of the XI Congress on Fertility and Sterility Lancaster, MTP Press, 1984, pp 311-316.

97 Yuzpe AA, Turlow HJ, Ramzy I, Leyson JI: Post-coital contraception - a pilot study. J Reprod Med 1974;30:12-18.

98 Bhattacharjee SK, Romeo J, Kononova ES et al: Postcoital contraception with levonorgestrel during the peri-ovulatory phase of the menstrual cycle. Task Force on PostOvulatory Methods for Fertility Regulation. Contraception 1987;36:257-286.

99 Randomized controlled trial of levonorgestrel versus the Yuzpe regimen of combined oral contraceptives for emergency contraception. Task Force on Postovulatory Methods of Fertility Regulation. Lancet 1998;352:428-433.

100 International Medical Advisory Panel, International Planned Parenthood Federation: IMAP statement on emergency contraception. IPPF Med Bull 2004;38:1-3.

101 von Hertzen H, Van Look PF: Research on new methods of emergency contraception. Fam Plann Perspect 1996;22:62-68.

102 Comparison of three single doses of mifepristone as emergency contraception: a randomized trial. Task Force on Post-Ovulatory Methods for Fertility Regulation. Lancet 1999;353:697-702. 
103 von Hertzen H, Piaggio G, Ding J, et al: Low dose mifepristone and two regimens of levonorgestrel for emergency contraception: a WHO multicentre randomized trial. Lancet 2002;360:1803-1810.

104 Cheng L, Gülmezoglu AM, Piaggio G, Ezcurra E, Van Look PF: Interventions for emergency contraception. Cochrane Database Syst Rev 2008;16:CD001324.

105 Remme JH, Adam T, Becerra-Posada F, et al: Defining research to improve health systems. PLoS Med 2010;7:e1001000.

106 Peterson HB, d'Arcangues C, Haidar J, et al: Accelerating science-driven solutions to challenges in global reproductive health: a new framework for moving forward. Obstet Gynecol 2011;117:720-726.

-107 Peterson HB, Haidar J, Merialdi M, et al: Preventing maternal and newborn deaths globally: using innovation and science to address challenges in implementing lifesaving interventions. Obstet Gynecol 2011; 117:720-726.

-108 Huntington D, Zaky HH, Shawky S, Fattah FA, El-Hadary E: Impact of a service provider incentive payment scheme on quality of reproductive and child-health services in Egypt. J Health Popul Nutr 2010;28:273280.

109 Huntington D, Banzon E, Recidoro ZD: A systems approach to improving maternal health in the Philippines. Bull World Health Organ 2012;90:104-110.

-110 Althabe F, Buekens P, Bergel E et al, Guidelines Trial Group: A behavioral intervention to improve obstetrical care. N Engl J Med 2008;358:1929-1940.

- 111 Gülmezoglu AM, Langer A, Piaggio G, Lumbiganon P, Villar J, Grimshaw J: Cluster randomised trial of an active, multifaceted educational intervention based on the WHO Reproductive Health Library to improve obstetric practices. Br J Obstet Gynaecol 2007;114:16-23.

-112 Althabe F, Belizán JM, Villar J, et al, Latin American Caesarean Section Study Group: Mandatory second opinion to reduce rates of unnecessary caesarean sections in Latin America: a cluster randomised controlled trial. Lancet 2004;363:1934-1940.

-113 Fajans P, Simmons R, Ghiron L: Helping public sector health systems innovate: the strategic approach to strengthening reproductive health policies and programs. Am J Public Health 2006;96:435-440.

114 World Health Organization: Practical guidance for scaling up health service innovations. Geneva, ExpandNet/WHO, 2009.

- 115 Mohllajee AP, Curtis KM, Flanagan RG, Rinehart W, Gaffield ML, Peterson HB: Keeping up with evidence a new system for WHO's evidence-based family planning guidance. Am J Prev Med 2005;28:483490.
116 Curtis KM, Peterson HB, d'Arcangues C: Keeping evidence-based recommendations up to date: the World Health Organization's global guidance for family planning. Contraception 2009;80:323-324.

117 World Health Organization: Medical eligibility criteria for contraceptive use, ed 4 . Geneva, WHO, 2010.

118 World Health Organization: Selected practice recommendations for contraceptive use, 2008 update. Geneva, WHO, 2008.

119 World Health Organization: Decisionmaking tool for family planning clients and providers. Geneva, WHO, 2005

120 Johnson SL, Kim YM, Church K: Towards client-centered counseling: development and testing of the WHO Decision-Making Tool. Patient Educ Couns 2010;81:355-361.

121 World Health Organization: Family planning: a global handbook for providers, 2007 (updated in 2008). Geneva, WHO, 2008.

122 World Health Organization: Induced abortion: report of a Scientific Group meeting. WHO Technical Report Series 623. Geneva, WHO, 1977.

123 Bygdeman M: The use of prostaglandins and their analogues for abortion. Clin $\mathrm{Ob}-$ stet Gynaecol 1984;11:573-584.

124 UNDP, UNFPA, WHO, World Bank Special Programme of Research, Development and Research Training in Human Reproduction, Task Force on Post-Ovulatory Methods of Fertility Regulation: Lowering the doses of mifepristone and gemeprost for early abortion: a randomized controlled trial. Br J Obstet Gynaecol 2001;108:738742 .

125 Tang OS, Lee SW, Ho PC: A prospective randomized study on the measured blood loss in medical termination of early pregnancy by three different misoprostol regimens after pretreatment with mifepristone. Hum Reprod 2002;17:2865-2868.

126 von Hertzen H, Honkanen H, Piaggio G, et al: WHO multinational study of three misoprostol regimens after mifepristone for early medical abortion. 1. Efficacy. Br J Obstet Gynaecol 2003;110:808-818.

127 Honkanen H, Piaggio G, Hertzen H, et al: WHO multinational study of three misoprostol regimens after mifepristone for early medical abortion. 2. Side effects and women's perceptions. Br J Obstet Gynaecol 2004;111:715-725.

-128 von Hertzen H, Piaggio G, Huong NT, et al: Efficacy of two intervals and two routes of administration of misoprostol for termination of early pregnancy: a randomized controlled equivalence trial. Lancet 2007;369: 1938-1946.

129 von Hertzen H, Piaggio G, Wojdyla D, et al: Comparison of vaginal and sublingual misoprostol for second trimester abortion: randomized controlled equivalence trial. Hum Reprod 2009;24:106-112.
130 von Hertzen H, Piaggio G, Wojdyla D, et al: Two mifepristone doses and two intervals of misoprostol administration for termination of early pregnancy: a randomized controlled equivalence trial. Br J Obstet Gynaecol 2009;116:381-389.

131 Johnson BR, Horga M, Fajans P: A strategic assessment of abortion and contraception in Romania. Reprod Health Matters 2004; 12(suppl 24):184-194.

132 Bazarragchaa T, Khishgee S, Johnson BR, Strategic Assessment Team: Applying the WHO Strategic Approach to strengthening first and second trimester abortion services in Mongolia. Reprod Health Matters 2008; 16:127-134

-133 Jackson E, Johnson BR, Gebreselassie H, Kangaude GD, Mhango C: A strategic assessment of unsafe abortion in Malawi. Reprod Health Matters 2011;19:133-143.

134 Warriner IK, Meirik O, Hoffman M, et al: Rates of complication in first-trimester manual vacuum aspiration abortion done by doctors and mid-level providers in South Africa and Vietnam: a randomised controlled equivalence trial. Lancet 2006;368: 1965-1972.

135 Warriner IK, Wang D, Huong NT, et al: Can midlevel health-care providers administer early medical abortion as safely and effectively as doctors? A randomised controlled equivalence trial in Nepal. Lancet 2011;377: 1155-1161.

-136 Sedgh G, Singh S, Shah IH, Ahman E, Henshaw SK, Bankole A: Induced abortion: incidence and trends worldwide from 1995 to 2008. Lancet 2012;379:625-632.

137 World Health Organization: Safe abortion: technical and policy guidance for health systems, ed 2. Geneva, WHO, 2012. http:// www.who.int/reproductivehealth/publications/unsafeabortion/9789241548434/en/ index.html

138 Which anticonvulsant for women with eclampsia? Evidence from the Collaborative Eclampsia Trial. Lancet 1995;345:1455-1463.

139 Altman D, Carroli G, Duley L, et al, Magpie Trial Collaboration Group: Do women with pre-eclampsia, and their babies, benefit from magnesium sulphate? The Magpie Trial: a randomised placebo-controlled trial. Lancet 2002;359:1877-1890.

140 Villar J, Purwar M, Merialdi M, et al, WHO Vitamin C and Vitamin E trial group: World Health Organization multicentre randomised trial of supplementation with vitamins $\mathrm{C}$ and $\mathrm{E}$ among pregnant women at high risk for pre-eclampsia in populations of low nutritional status from developing countries. Br J Obstet Gynaecol 2009; 116:780-788.

141 Widmer M, Villar J, Benigni A, CondeAgudelo A, Karumanchi SA, Lindheimer M: Mapping the theories of preeclampsia and the role of angiogenic factors: a systematic review. Obstet Gynecol 2007;109:168180. 
142 von Dadelszen P, Payne B, Li J, et al, PIERS Study Group: Prediction of adverse maternal outcomes in pre-eclampsia: development and validation of the full PIERS model. Lancet 2011;377:219-227.

143 Gülmezoglu AM, Villar J, Ngoc NT, et al, WHO Collaborative Group to Evaluate Misoprostol in the Management of the Third Stage of Labour: WHO multicentre randomised trial of misoprostol in the management of the third stage of labour. Lancet 2001;358:689-695.

144 Widmer M, Blum J, Hofmeyr GJ, et al: Misoprostol as an adjunct to standard uterotonics for treatment of post-partum haemorrhage: a multicentre, double-blind randomised trial. Lancet 2010;375:18081813.

- 145 Gülmezoglu AM, Lumbiganon P, Landoulsi S, et al: Active management of the third stage of labour with and without controlled cord traction: a randomised, controlled, non-inferiority trial. Lancet 2012;379: 1721-1727.

146 Villar J, Ba'aqeel H, Piaggio G, et al, WHO Antenatal Care Trial Research Group: WHO antenatal care randomised trial for the evaluation of a new model of routine antenatal care. Lancet 2001;357:1551-1564.

147 WHO study group on female genital mutilation and obstetric outcome, Banks E, Meirik O, Farley T, Akande O, Bathija H, Ali M: Female genital mutilation and obstetric outcome: WHO collaborative prospective study in six African countries. Lancet 2006;367:1835-1841.

- 148 Betrán AP, Merialdi M, Lauer JA, et al: Rates of caesarean section: analysis of global, regional and national estimates. Paediatr Perinat Epidemiol 2007;21:98-113.

-149 Shah A, Fawole B, M’imunya JM, et al: Cesarean delivery outcomes from the WHO global survey on maternal and perinatal health in Africa. Int $J$ Gynaecol Obstet 2009;107:191-197.

150 Villar J, Valladares E, Wojdyla D, et al, WHO 2005 global survey on maternal and perinatal health research group: Caesarean delivery rates and pregnancy outcomes: the 2005 WHO global survey on maternal and perinatal health in Latin America. Lancet 2006;367:1819-1829.

-151 Lumbiganon P, Laopaiboon M, Gülmezoglu AM, et al, World Health Organization Global Survey on Maternal and Perinatal Health Research Group: Method of delivery and pregnancy outcomes in Asia: the WHO global survey on maternal and perinatal health 2007-08. Lancet 2010;375: 490-499.

152 Torloni MR, Daher S, Betrán AP, et al: Portrayal of caesarean section in Brazilian women's magazines: 20 year review. Br Med J 2011;342:d276.

153 Gibbons L, Belizan JM, Lauer JA, Betran AP, Merialdi M, Althabe F: Inequities in the use of cesarean section deliveries in the world. Am J Obstet Gynecol 2012;206:331. e1-e19.

154 Torloni MR, Betran AP, Souza JP, et al: Classifications for cesarean section: a systematic review. PLoS One 2011;6:e14566.

155 Rouet F, Foulongne V, Viljoen J, et al, WHO/ANRS 1289 Kesho Bora Study Group: Comparison of the generic HIV Viral Load assay with the Amplicor HIV-1 monitor v1.5 and Nuclisens HIV-1 Easy Q v1.2 techniques for plasma HIV-1 RNA quantitation of non-B subtypes: the Kesho Bora preparatory study. J Virol Methods 2010;163:253-257.

156 Viljoen J, Gampini S, Danaviah S, et al, WHO/ANRS 1289 Kesho Bora Study Group: Dried blood spot HIV-1 RNA quantification using open real-time systems in South Africa and Burkina Faso. J Acquir Immune Defic Syndr 2010;55:290-298.

157 Kania D, Fao P, Valéa D, et al, WHO/ANRS 1289 Kesho Bora Study Group in Burkina Faso: Low prevalence rate of indeterminate serological human immunodeficiency virus results among pregnant women from Burkina Faso. West Afr J Clin Microbiol 2010;48:1333-1336.

158 Kesho Bora Study Group: Eighteen-month follow-up of HIV-1-infected mothers and their children enrolled in the Kesho Bora study observational cohorts. J Acquir Immune Defic Syndr 2010;54:533-541.

159 Cames C, Saher A, Ayassou KA, Cournil A, Meda N, Simondon KB: Acceptability and feasibility of infant feeding options: experiences of HIV-infected mothers in the World Health Organization Kesho Bora motherto-child transmission prevention (PMTCT) trial in Burkina Faso. Matern Child Nutr 2010;6:253-265.

160 Kesho Bora Study Group, de Vincenzi I: Triple antiretroviral compared with zidovudine and single-dose nevirapine prophylaxis during pregnancy and breastfeeding for prevention of mother-to-child transmission of HIV-1 (Kesho Bora study): a randomised controlled trial. Lancet Infect Dis 2011;11:171-180.

161 Kesho Bora Study Group: Safety and effectiveness of antiretroviral drugs during pregnancy, delivery and breastfeeding for prevention of mother-to-child transmission of HIV-1: the Kesho Bora multicentre collaborative study rationale, design, and implementation challenges. Contemp Clin Trials 2011;32:74-85.

162 Irungu E, Chersich MF, Sanon C, et al, Kesho Bora Study Group: Changes in sexual behaviour among HIV-infected women in west and east Africa in the first 24 months after delivery. AIDS 2012;26:997-1007.

163 The Kesho Bora Study Group: Maternal HIV-1 disease progression 18-24 months post-delivery according to antiretroviral prophylaxis regimen (triple-antiretroviral prophylaxis during pregnancy and breastfeeding vs zidovudine/single-dose nevira- pine prophylaxis): the Kesho Bora randomized-controlled trial. Clin Infect Dis 2012; 55:449-460.

164 World Health Organization, HIV/AIDS Programme: Antiretroviral therapy for HIV infection in adults and adolescents: recommendations for a public health approach 2010 revision. Geneva, WHO, 2010.

165 World Health Organization: Towards universal access: scaling up priority HIV/AIDS interventions in the health sector - progress report 2010. Geneva, WHO, 2011, pp 145-150.

166 Deperthes BD, Meheus A, O’Reilly K, Broutet N: Maternal and congenital syphilis programmes: case studies in Bolivia, Kenya and South Africa. Bull World Health Organ 2004;82:410-416.

167 Munkhuu B, Liabsuetrakul T, Chongsuvivatwong $\mathrm{V}$, McNeil E, Janchiv R: One-stop service for antenatal syphilis screening and prevention of congenital syphilis in Ulaanbaatar, Mongolia: a cluster randomized trial. Sex Transm Dis 2009;36:714-720.

168 Munkhuu B, Liabsuetrakul T, McNeil E, Janchiv R: Feasibility of one-stop antenatal syphilis screening in Ulaanbaatar, Mongolia: women and providers perspectives. Southeast Asian J Trop Med Public Health 2009; 40:861-870.

169 World Health Organization, Department of Reproductive Health and Research: The global elimination of congenital syphilis: rationale and strategy for action. Geneva, WHO, 2007, p 48.

170 World Health Organization: Prevention of cervical cancer through screening using visual inspection with acetic acid (VIA) and treatment with cryotherapy, 2009. 2012. http://www.who.int/reproductivehealth/ publications/cancers/9789241503860/en/ index.html.

171 Santesso N, Schünemann H, Blumenthal P, et al, World Health Organization Steering Committee for the Recommendations on the Use of Cryotherapy for Cervical Cancer Prevention: World Health Organization Guidelines: use of cryotherapy for cervical intraepithelial neoplasia. Int J Gynaecol Obstet 2012;118:97-102.

172 World Health Organization, Department of Reproductive Health and Research: WHO guidelines: use of cryotherapy for cervical intraepithelial neoplasia. Geneva, WHO, 2011, p 28.

173 World Health Organization, Department of Reproductive Health and Research and Department of Chronic Diseases and Health Promotion: Comprehensive cervical cancer control: a guide to essential practice. Geneva, WHO, 2006, p 284.

174 Warriner IK, Jejeebhoy SJ, Shah IH: Risk taking behaviours among adolescents in developing countries: evidence from a WHO research initiative (oral presentation). Population Association of America, Annual Meeting, Detroit, 2009. 
175 Foeg M, Damgaard-Petersen F, Gormsen J, Knudsen JB, Schou G: Oral levonorgestreltestosterone effects on spermatogenesis, hormone levels, coagulation factors and lipoproteins in normal men. Contraception 1980;21:381-391.

176 Paulsen CA: Androgen-progestogen combinations; in Zatuchni GI, Goldsmith A, Spieler JM, Sciarra JJ (eds): Male Contraception: Advances and Future Prospects. Philadelphia, Harper \& Row, 1986, pp 30303.

177 World Health Organization, Special Programme of Research in Human reproduction: Annual Technical Report for 1996. Geneva, WHO, 1997.

178 World Health Organization, Special Programme of Research in Human Reproduction: Annual Technical Report for 1995. Geneva, WHO, 1996

179 WHO Laboratory Manual for the Examination and Processing of Human Semen, ed 5. Geneva, WHO, 2010

180 World Health Organization: Prevention and treatment of HIV and other sexually transmitted infections among men who have sex with men and transgender people: recommendations for a public health approach. 2011. http://www.who.int/hiv/pub/ guidelines/msm_guidelines2011/en/.

181 Gruskin S, Cottingham J, Martin Hilber A, Kismodi E, Lincetto O, Roseman MJ: Using human rights to improve maternal and neonatal health: history, connections and a proposed practical approach. Bull World Health Organ 2008;86:589-593.

182 Cottingham J, Kismodi E, Hilber AM, Lincetto O, Stahlhofer M, Gruskin S: Using human rights for sexual and reproductive health: improving legal and regulatory frameworks. Bull World Health Organ 2010;88:551-555.

183 World Health Organization: Sexual and reproductive health and human rights: a tool for examining laws, regulations and policies. Geneva, WHO, in press.

184 United Nations, Department of Public Information: Secretary-General, in message on International Day, says violence against women is an atrocious manifestation of continued inequality. Press release SG/ SM/10225OBV/527/WOM/1524 dated 22 November 2005. http://www.un.org/News/ Press/docs/2005/sgsm10225.doc.htm.
85 Garcia-Moreno C, Heise L, Jansen HA, Ellsberg M, Watts C: Violence against women. Science 2005;310:1282-1283.

186 Benagiano G, Carrara S, Filippi V: Social and ethical determinants of sexuality. 2 . Gender-based violence. Eur J Contracept Reprod Health Care 2010;15:220-231.

187 García-Moreno C, Watts C, Jansen HA, Ellsberg M, Heise L: Responding to violence against women: WHO's multi-country study on women's health and domestic violence. Health Hum Rights 2003;6:113127.

188 García-Moreno C, Jansen H, Ellsberg M, Heise L, Watts CH: Prevalence of intimate partner violence: findings from the $\mathrm{WHO}$ multi-country study on women's health and domestic violence. Lancet 2006;368 1260-1269.

189 Ellsberg M, Jansen HA, Heise L, Watts CH, García-Moreno C, WHO Multi-country Study on Women's Health and Domestic Violence against Women Study Team: Intimate partner violence and women's physical and mental health in the WHO multicountry study on women's health and domestic violence: an observational study. Lancet 2008;371:1165-1172.

190 Pallitto CC, García-Moreno C, Jansen HA, Heise L, Ellsberg M, Watts C, WHO MultiCountry Study on Women's Health and Domestic Violence: Intimate partner violence, abortion and unintended pregnancy: results from the WHO multi-country study on women's health and domestic violence. Int J Obstet Gynecol, 2012, E-pub ahead of print.

191 Mundigo A, Indriso C (eds): Abortion in the Developing World: Findings from WHO Case Studies. New Delhi, Sage, 1998.

192 World Health Organization, Department of Reproductive Health and Research: Annual Technical Report 2000. Geneva, WHO, 2001.

193 World Health Organization: The World Health Report 2008 - Primary Health Care (Now More than Ever). http://www.who. int/whr/2008/en/.

194 World Health Organization: Sexual and reproductive health core competencies in primary care: attitudes, knowledge, ethics, human rights, leadership, management, teamwork, community work, education, counselling, clinical settings, service, provision. http://www.who.int/reproductivehealth/publications/health_systems/9789241501002/en/.
95 Oxman AD, Lavis JN, Fretheim A: Use of evidence in WHO recommendations. Lancet 2007;369:1883-1889.

196 Mohllajee AP, Curtis KM, Flanagan RG, Rinehart W, Gaffield ML, Peterson HB: Keeping up with evidence a new system for WHO's evidence-based family planning guidance. Am J Prev Med 2005;28:483490

197 Peterson HB, d'Arcangues C, Haidar J, Curtis KM, Merialdi M, Gülmezoglu AM, Say L, Mbizvo M: Accelerating sciencedriven solutions to challenges in global reproductive health: a new framework for moving forward. Obstet Gynecol 2011;117: $720-726$.

198 World Health Organization: The WHO application of ICD-10 to deaths during pregnancy, childbirth and puerperium: ICD MM. Geneva, WHO, 2012.

199 Say L, Souza JP, Pattinson RC, WHO Working Group on Maternal Mortality and Morbidity Classifications: Maternal near miss - towards a standard tool for monitoring quality of maternal health care. Best Pract Res Clin Obstet Gynaecol 2009;23: 287-296.

200 Trends in maternal mortality: 1990-2008 estimates developed by WHO, UNICEF, UNFPA, and the World Bank. Geneva, WHO, 2010.

201 Trends in maternal mortality: 1990 to 2010 WHO, UNICEF, UNFPA and the World Bank estimates. Geneva, WHO, 2012.

202 Khan KS, Wojdyla D, Say L, Gülmezoglu AM, Van Look PF: WHO analysis of causes of maternal death: a systematic review. Lancet 2006;367:1066-1074.

203 Beck S, Wojdyla D, Say L, et al: The worldwide incidence of preterm birth: a systematic review of maternal mortality and morbidity. Bull World Health Organ 2010;88 31-38.

204 Blencowe H, Cousens S, Oestergaard MZ, et al: National, regional, and worldwide estimates of preterm birth rates in the year 2010 with time trends since 1990 for selected countries: a systematic analysis and implications. Lancet 2012;379:2162-2172.

205 Cousens S, Stanton C, Blencowe H, et al: National, regional and global estimates of stillbirth rates in 2009 with trends since 1995. Lancet 2011;377:1319-1330. 